$1 \leqslant V$

\author{
أساليب الزراع للحد من التصحر بمحافظة مطروح

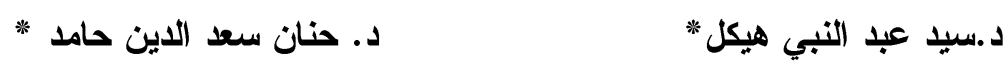

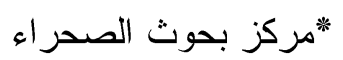

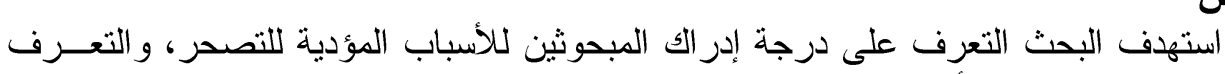

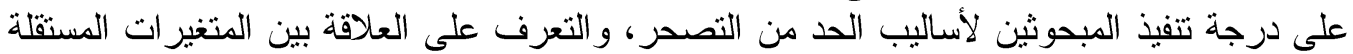

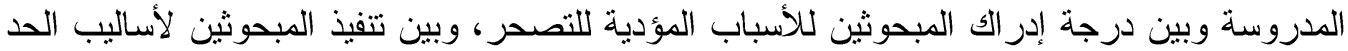

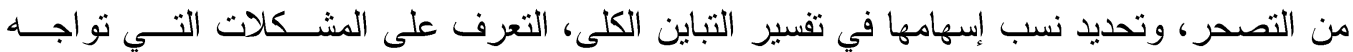

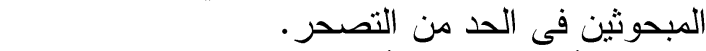

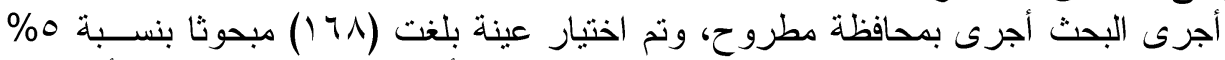

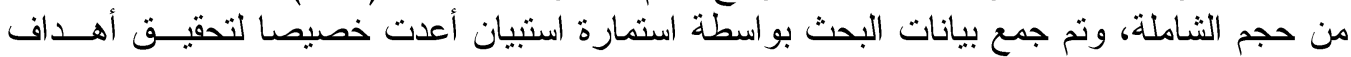

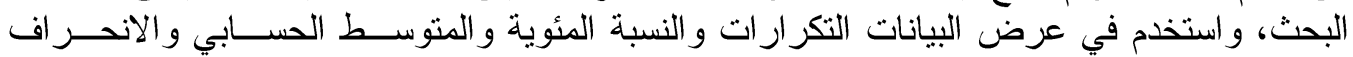

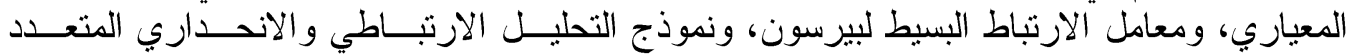

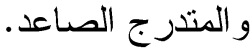
وتمثلت أهم النتائج فيما يلى الصن

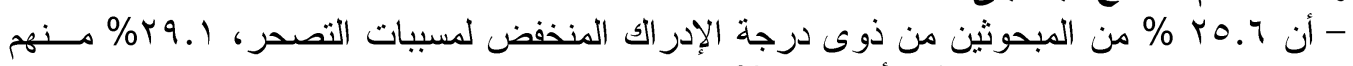

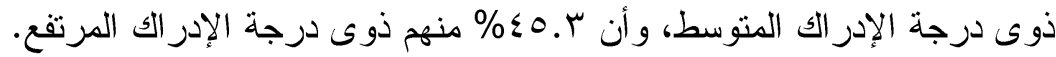

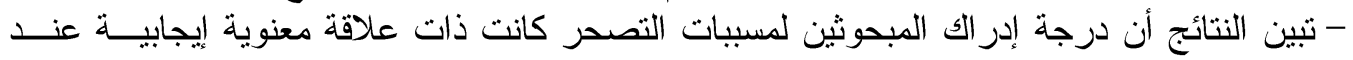

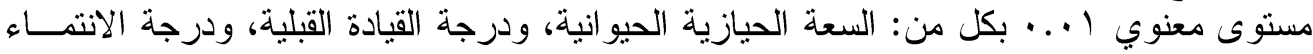

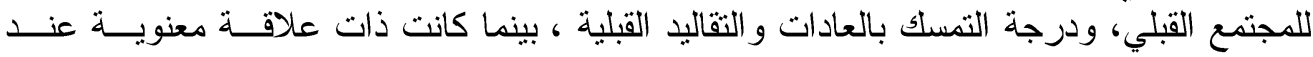

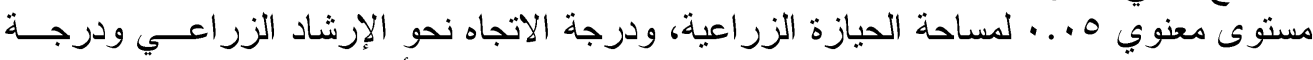

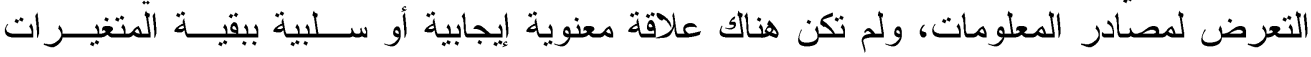

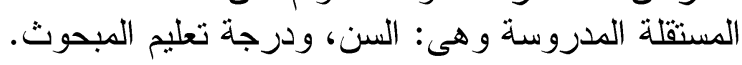

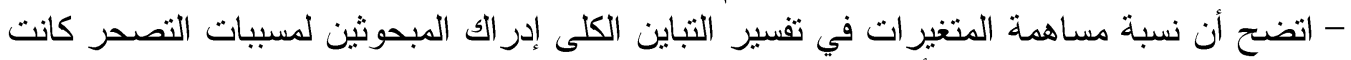

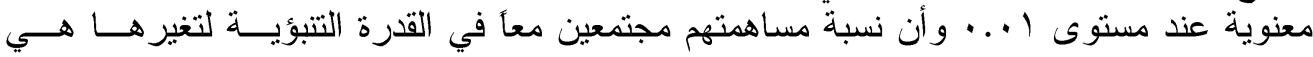

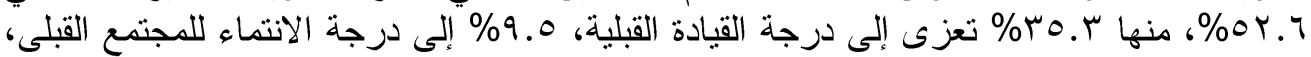

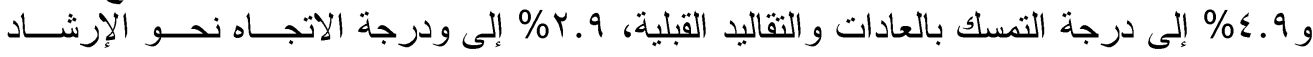
الزور اعي.

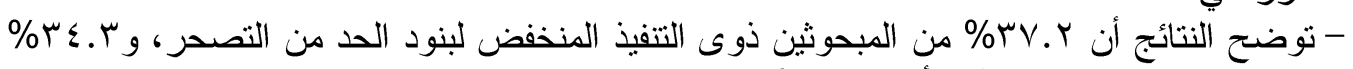

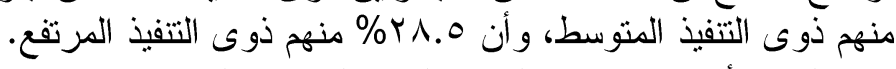

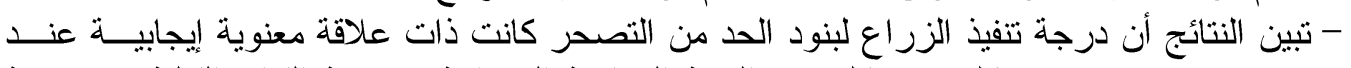

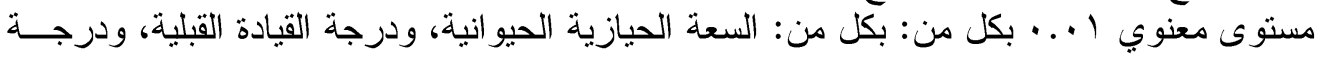

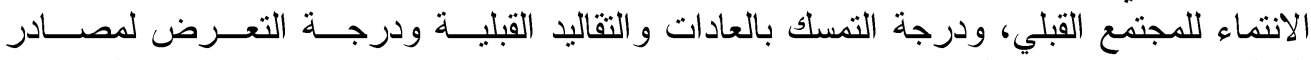

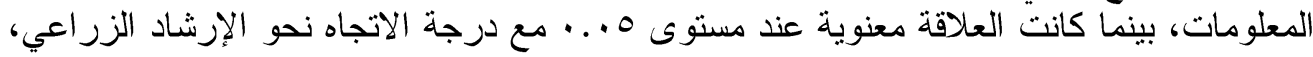

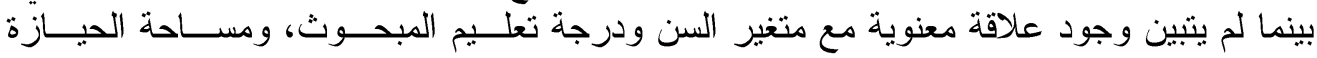
الز الزر اعية.

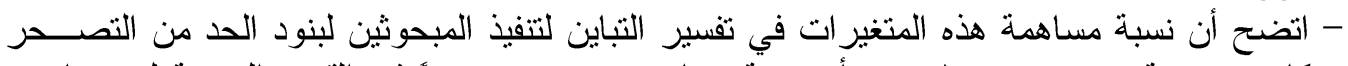

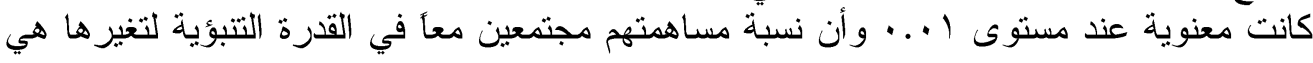

Fayoum J. Agric. Res. \& Dev., Vol. 30, No.1, January, 2016 
$1 \leqslant \Lambda$

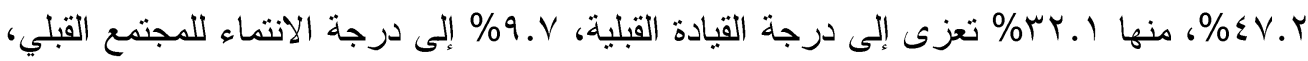

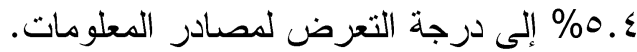

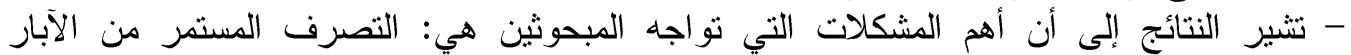

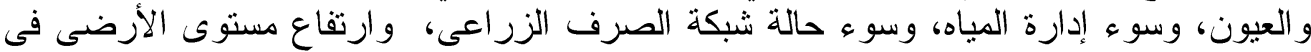

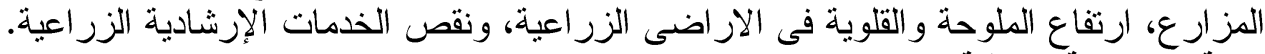

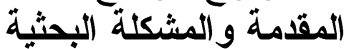

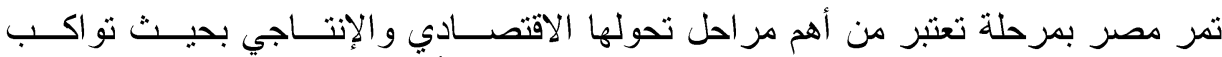

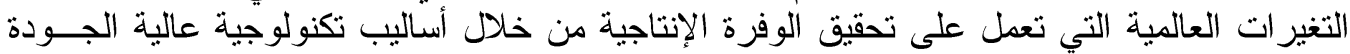

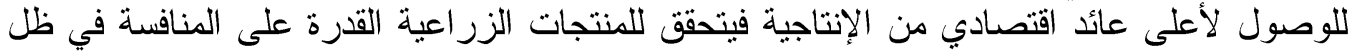

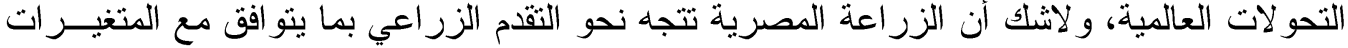

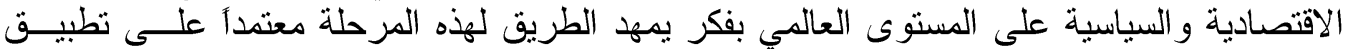
العديد من التكنولوجيات المتطورة.

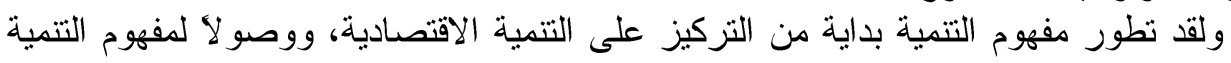

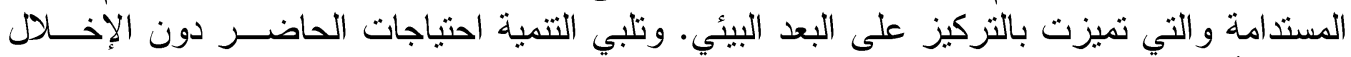

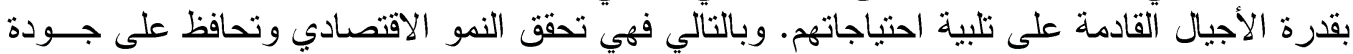

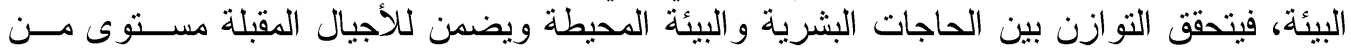

الرفاهية (GDRC, 2008, p2).

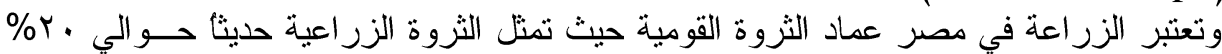

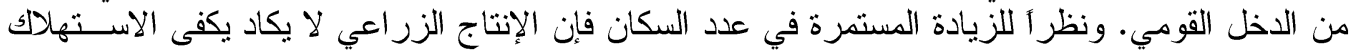

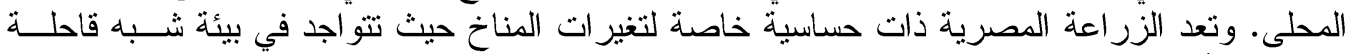

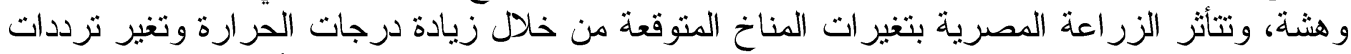

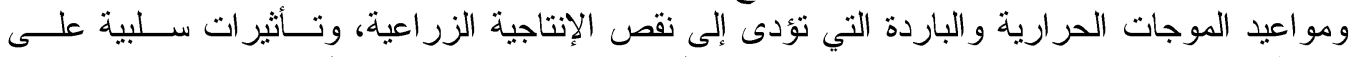

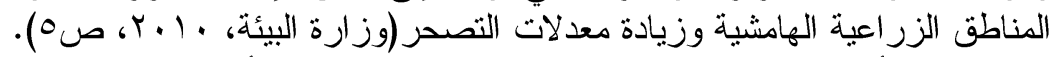

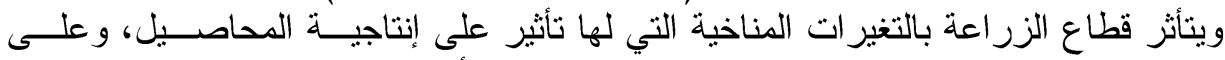

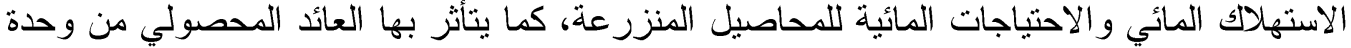

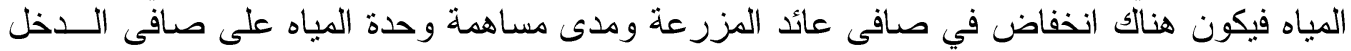

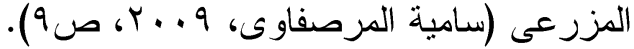

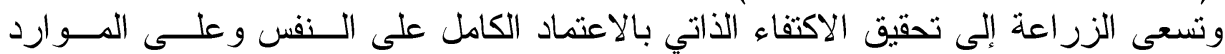

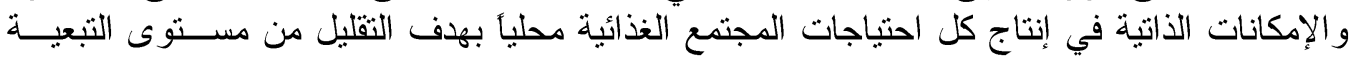

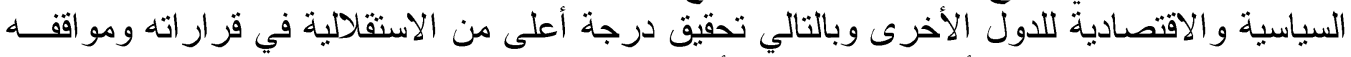

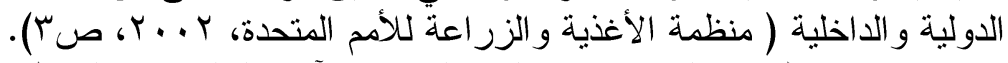

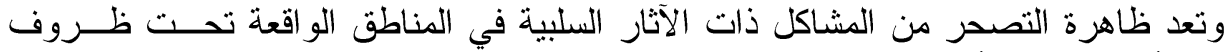

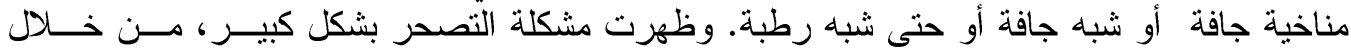

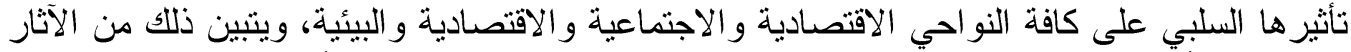

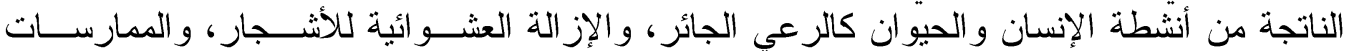

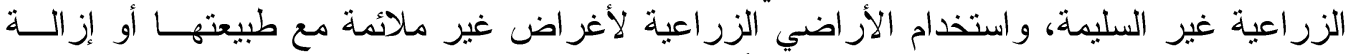

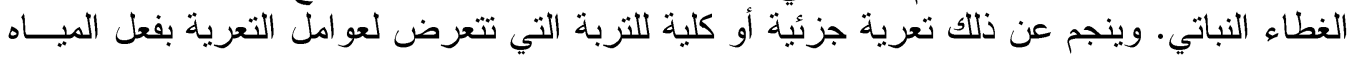

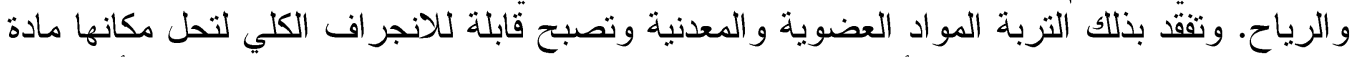

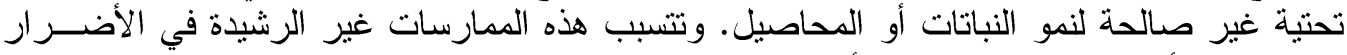

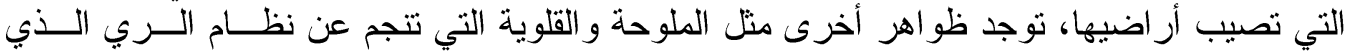

Fayoum J. Agric. Res. \& Dev., Vol. 30, No.1, January, 2016 


\section{$1 \leqslant 9$}

يصمم أو ينفذ بطريقة غير سليمة، ويعتبر الجفاف و التصحر من القيود الكبيرة التي تعـوق التنميــة

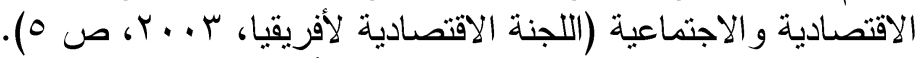

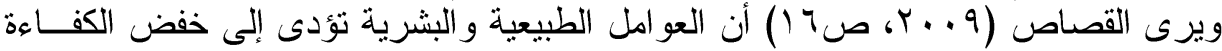

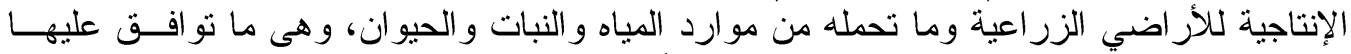

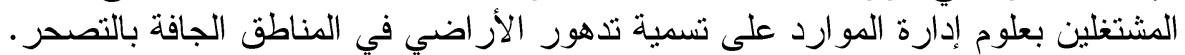

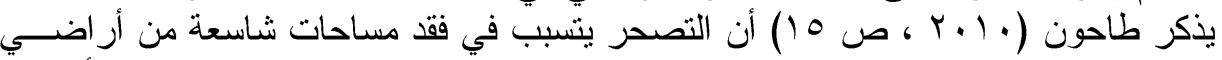

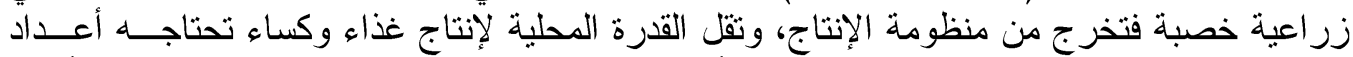

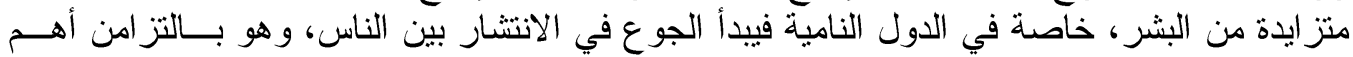

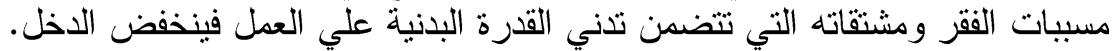

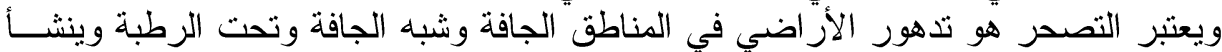

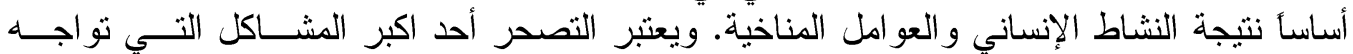

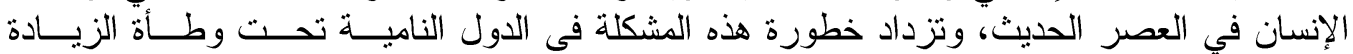

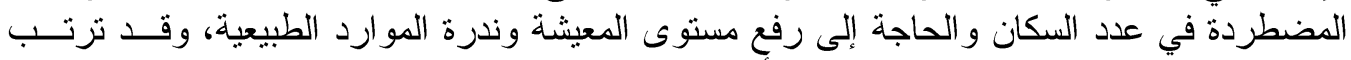

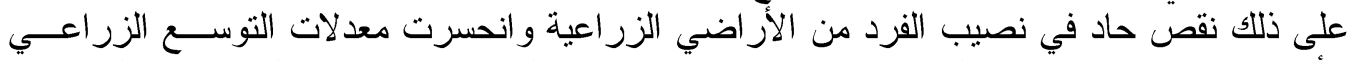

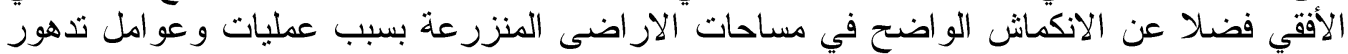

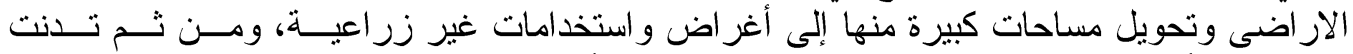

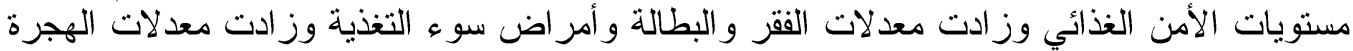

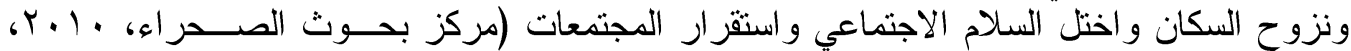

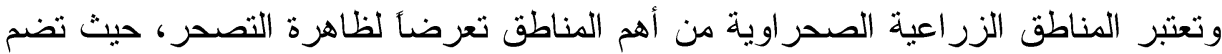

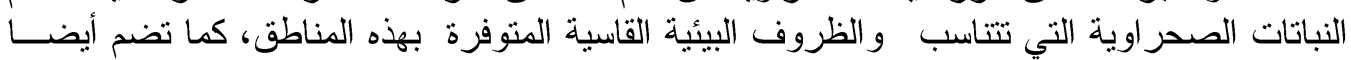

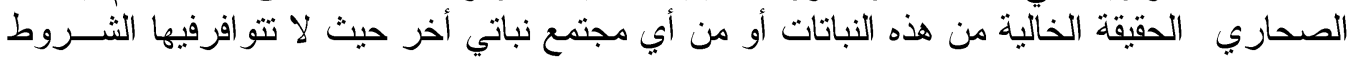

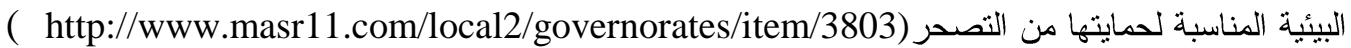

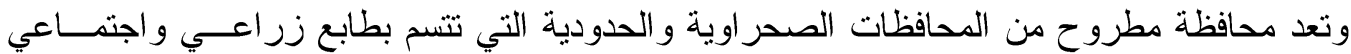

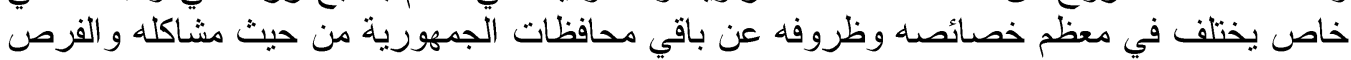

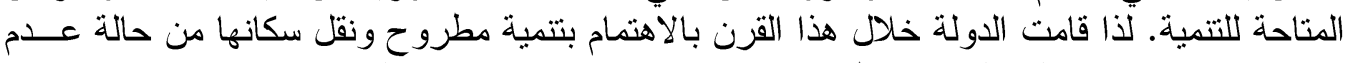

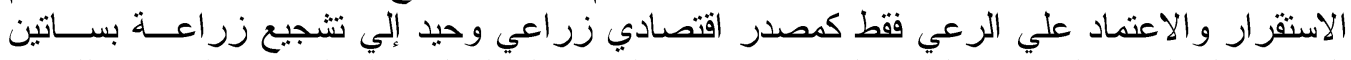

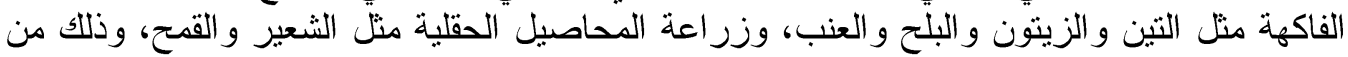

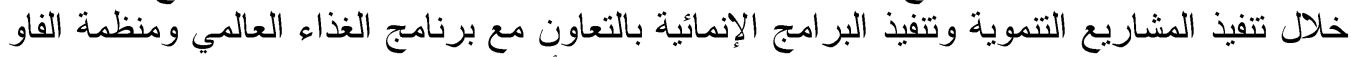

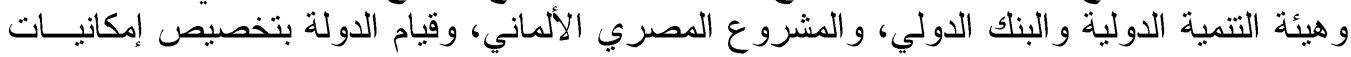

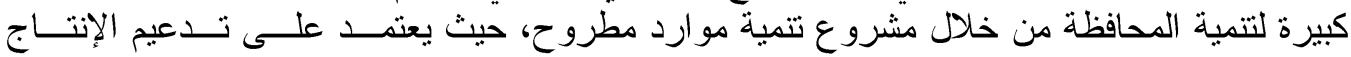

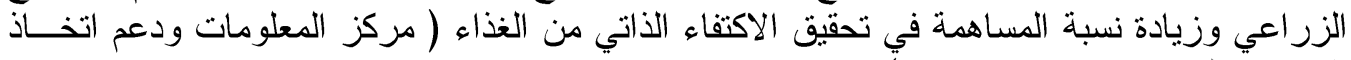

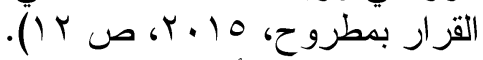

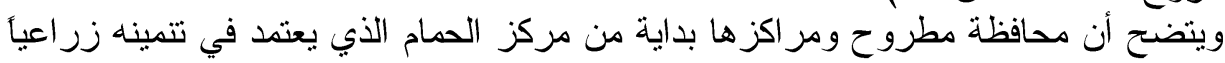

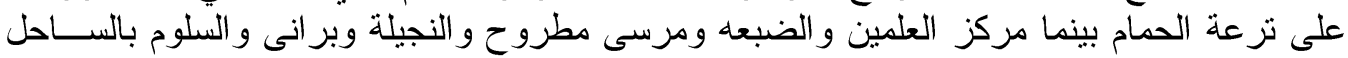

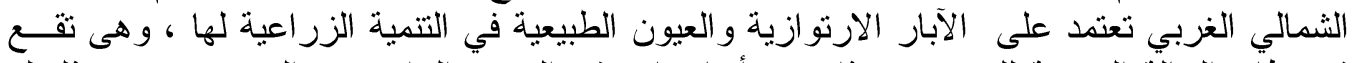

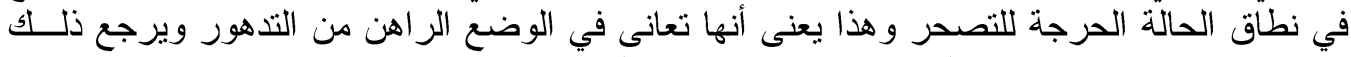

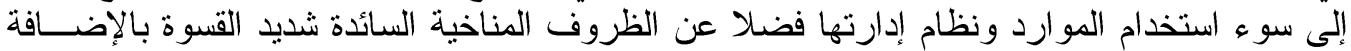

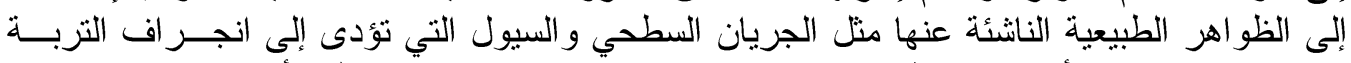

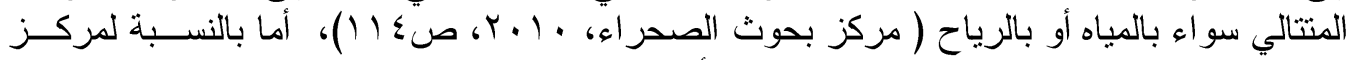

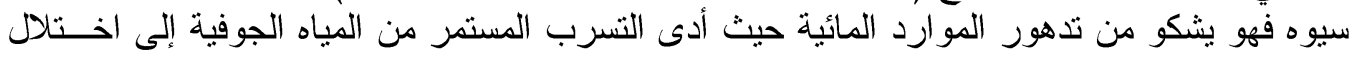

Fayoum J. Agric. Res. \& Dev., Vol. 30, No.1, January, 2016 
10.

الاتزان المائي الطبيعي بها حيث أن كمية المياه المتدفقة من العيون الطبيعية والتي يصعب التحكم في

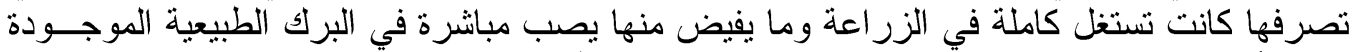

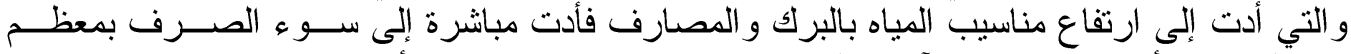

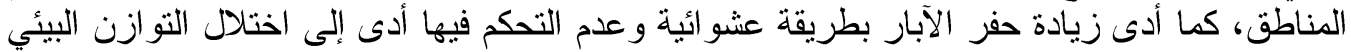

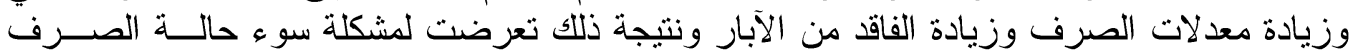

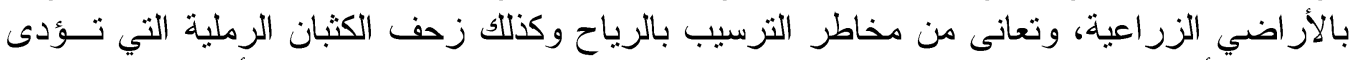

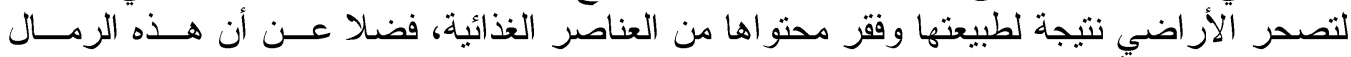

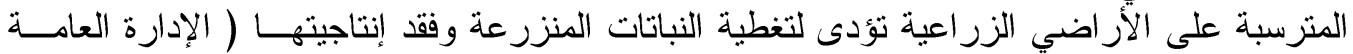

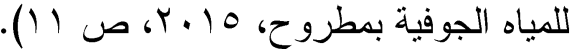

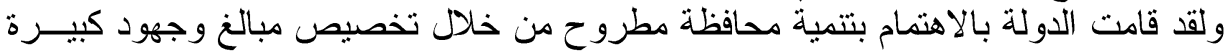

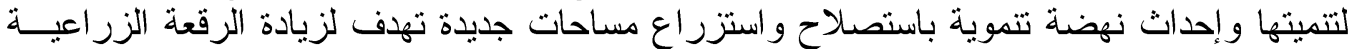

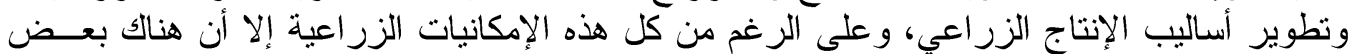

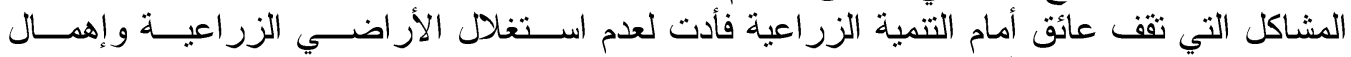

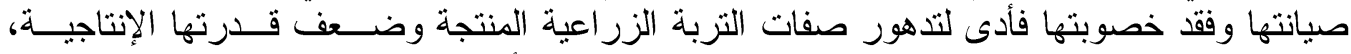

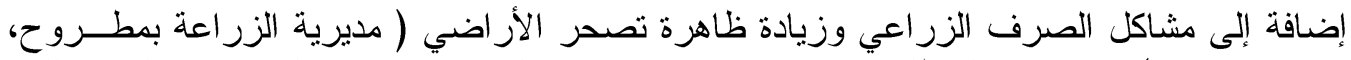

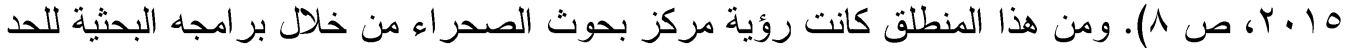

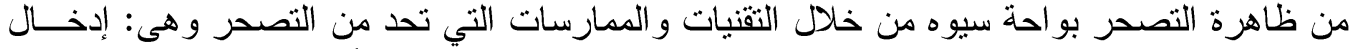

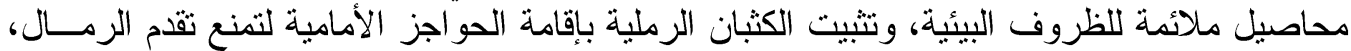

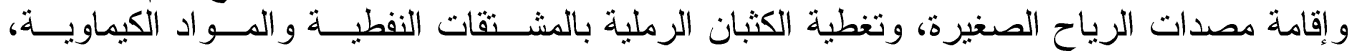

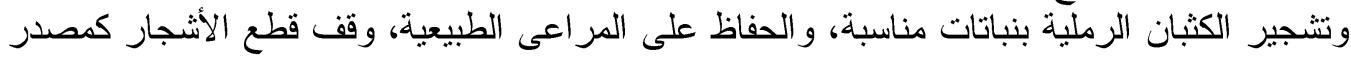

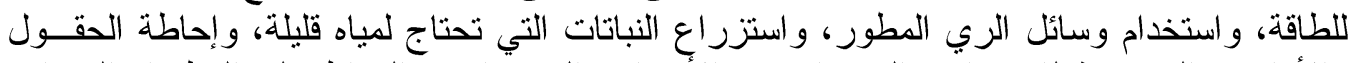

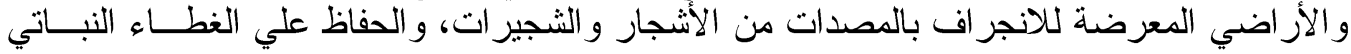

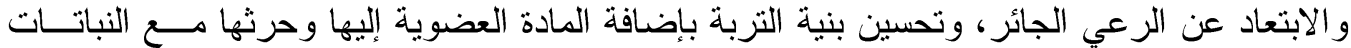

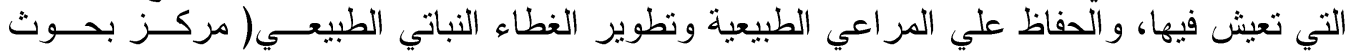

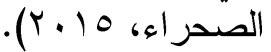

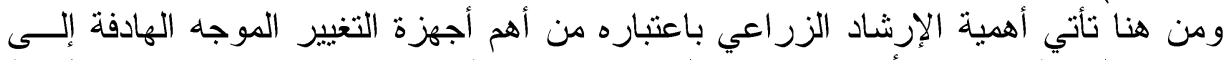

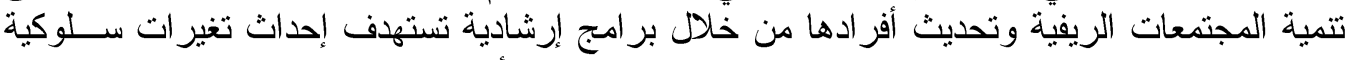

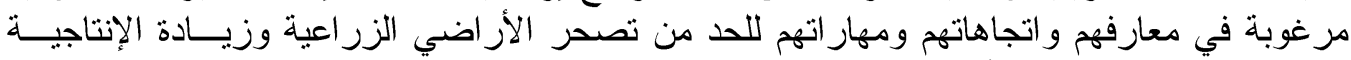

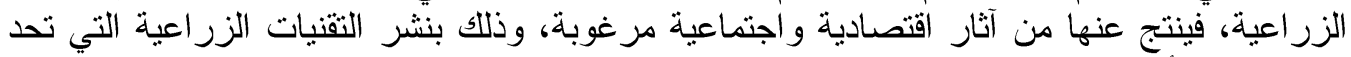

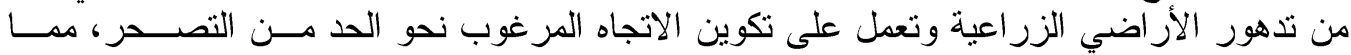

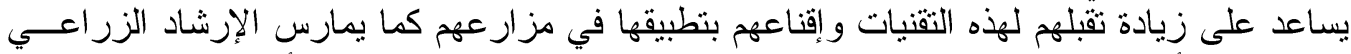

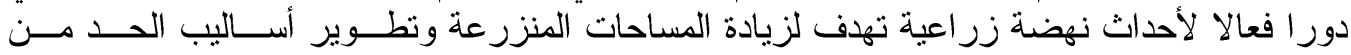

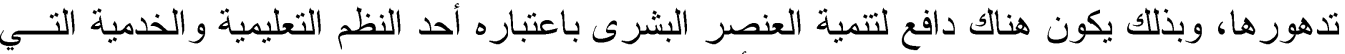

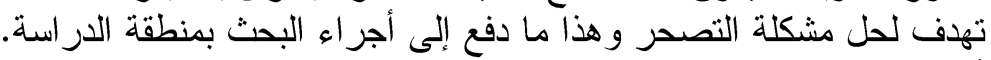

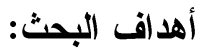

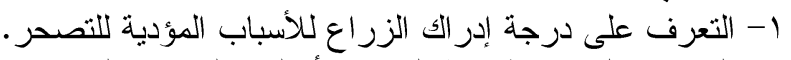

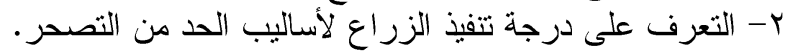

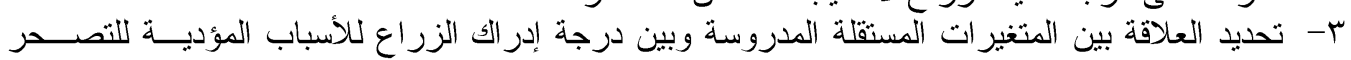
وتحديد نسب إسهامها في تفسير التباين الكلى. لتهن.

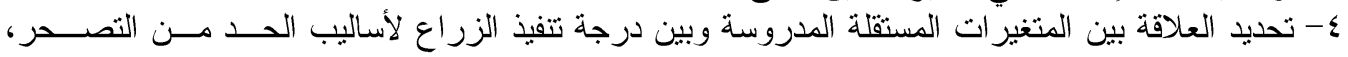
وتحديد نسب إسهامها في تفسير التباين الكلى. 0- التعرف على المشكلات ألنى تو اجه المبحوثين.

Fayoum J. Agric. Res. \& Dev., Vol. 30, No.1, January, 2016 


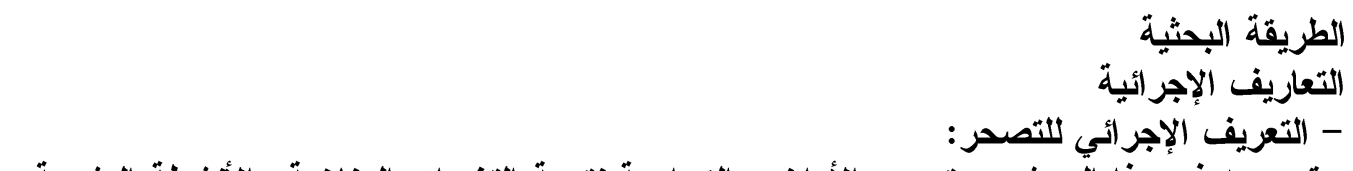
يقصد به في هذا البحث:هو لإنهري الإهور الأراضي الزراعية نتيجة التغيرات المناخية والأشثطة البشرية.

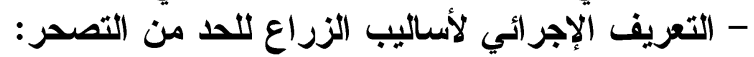

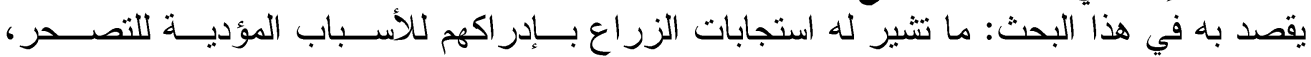

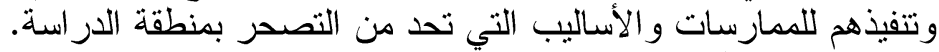

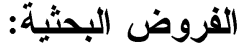
نظر آ لأن الهدف الأول والثاني والخامس أهداف استكثافية فلم بضع لهم فروض بحثية، أما

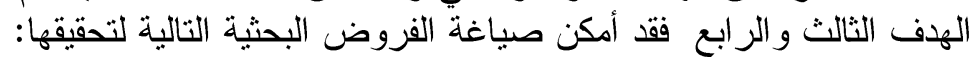

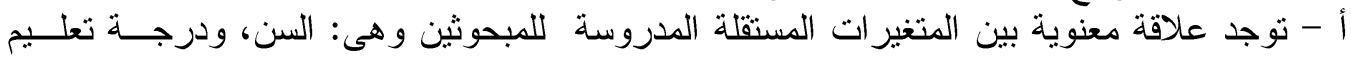

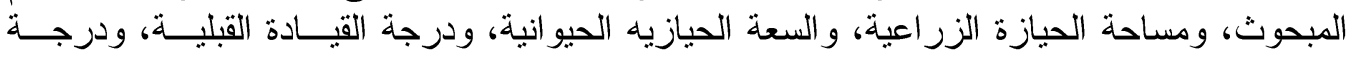

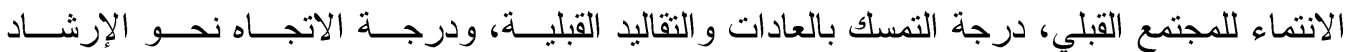

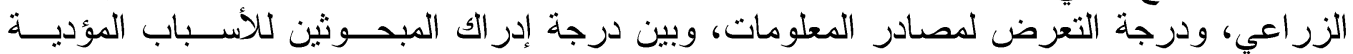

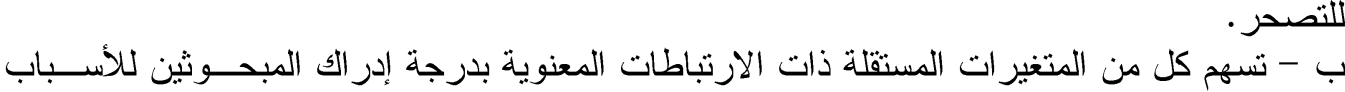
المؤدية للتصحر في تفسير التباين الكلى.

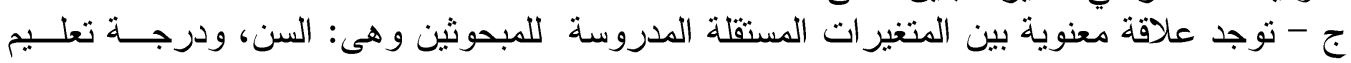

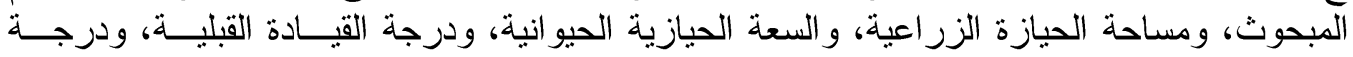

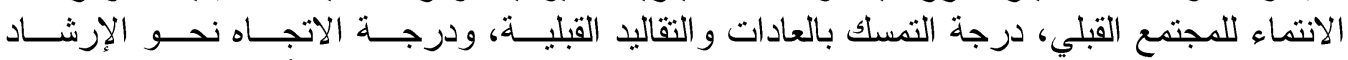

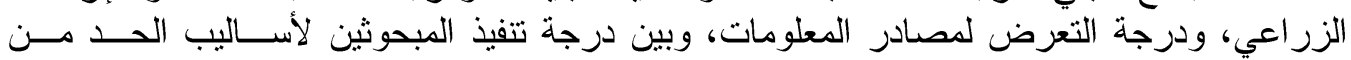

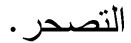
د - تسهم كل من المتغير ات المستقلة ذات الارتباطات المعنوية بدرجة تتفيذ المبحوثين لأساليب الحـــ من التصحر في تفسير التباين الكلى. دون. وتم وضع الفروض البحثية السابقة في صورتها الصفرية حتى يمكن اختبارها.

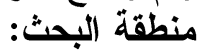

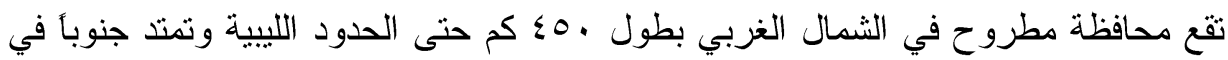

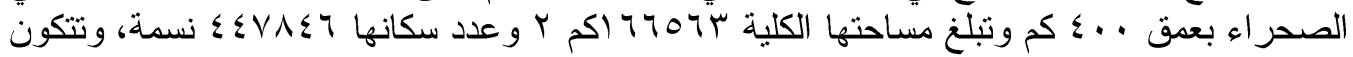

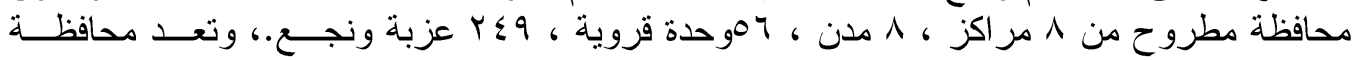

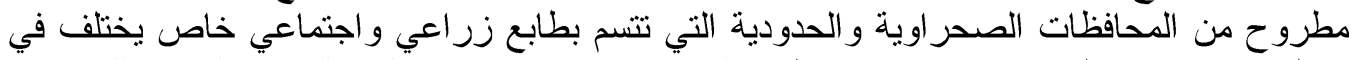

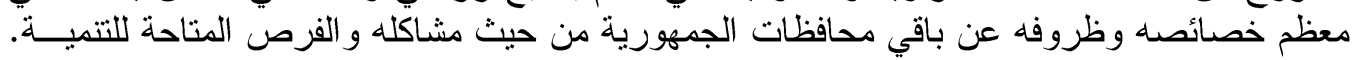

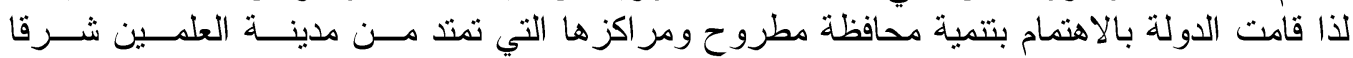

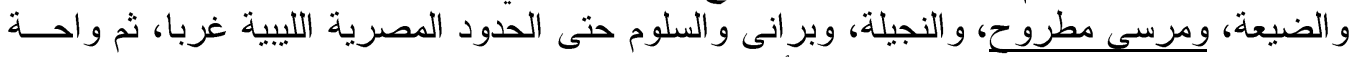

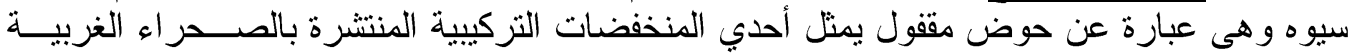

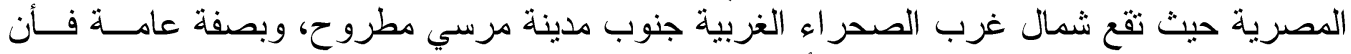

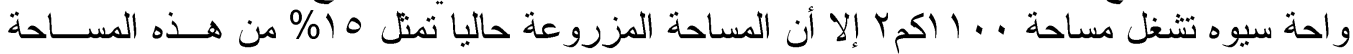

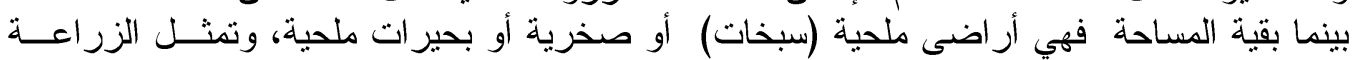

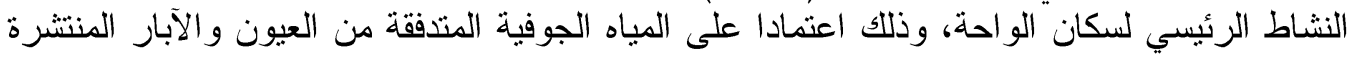

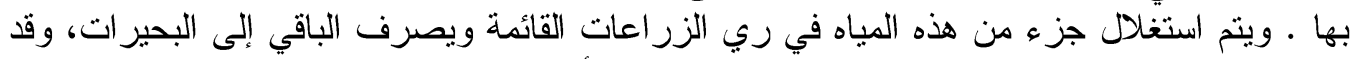

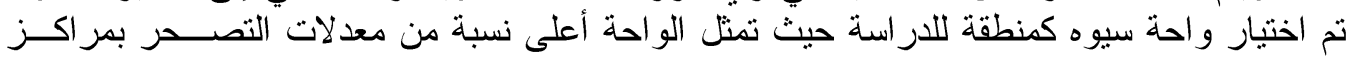

Fayoum J. Agric. Res. \& Dev., Vol. 30, No.1, January, 2016 


\section{lor}

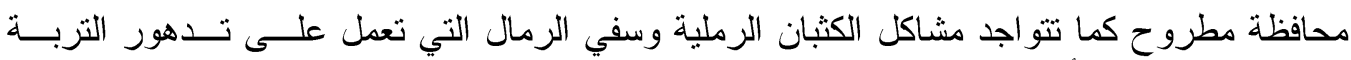

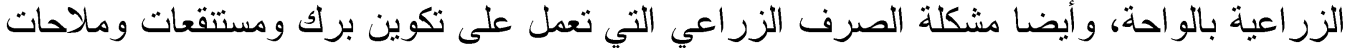

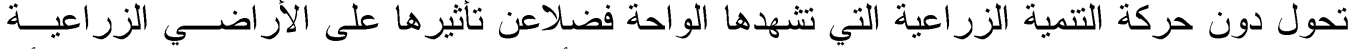

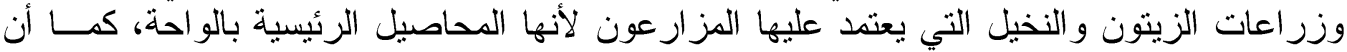

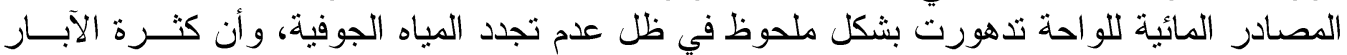

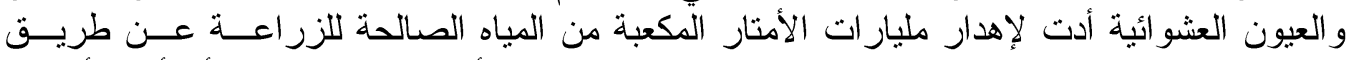

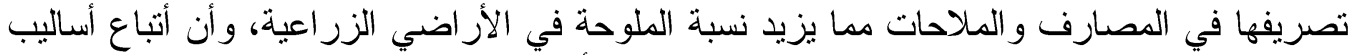

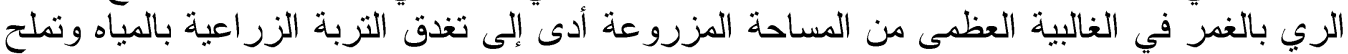

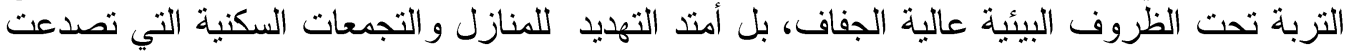

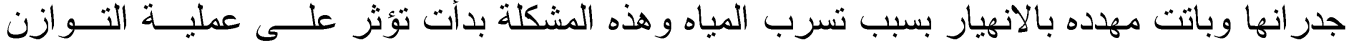

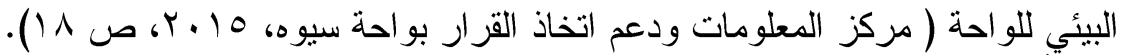

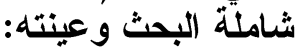

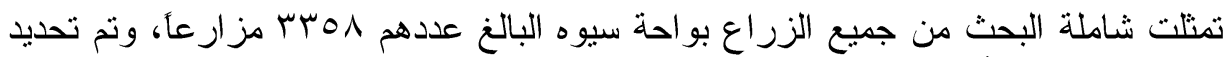

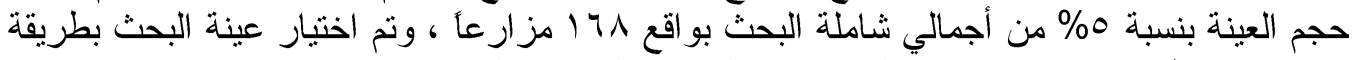

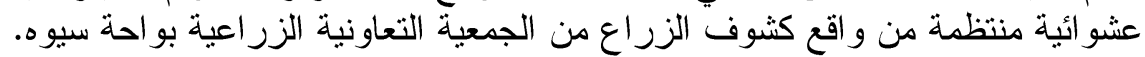

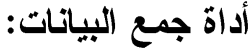

جمعت بيانات البحث عن طريق المقابلة الشخصية للمبحوثين بواسطة استمارة استبيان سبق

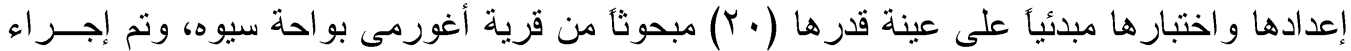

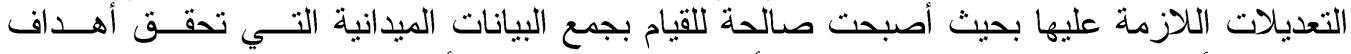

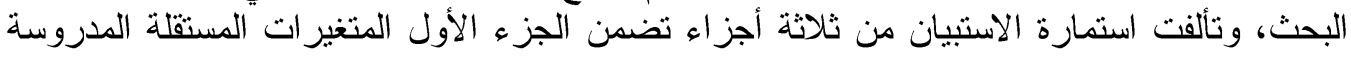

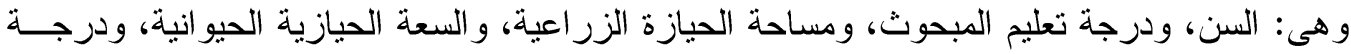

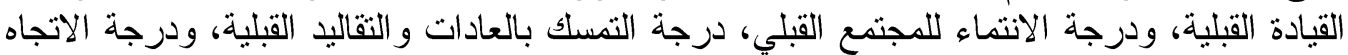

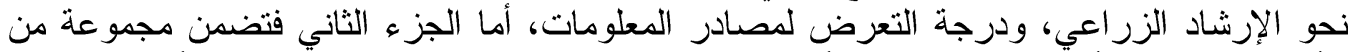

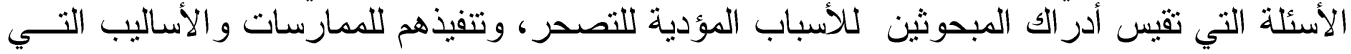

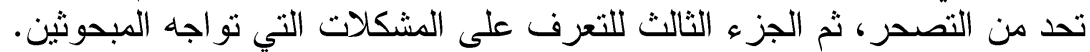

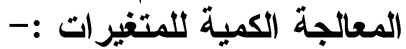

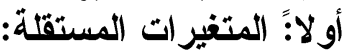

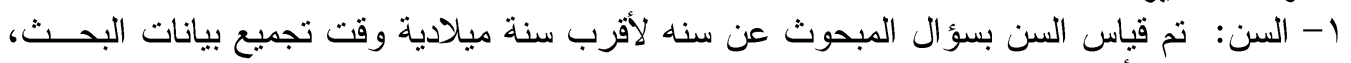

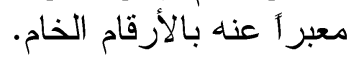

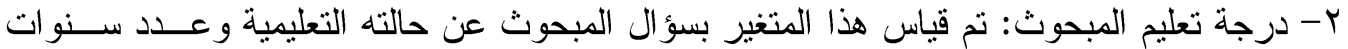

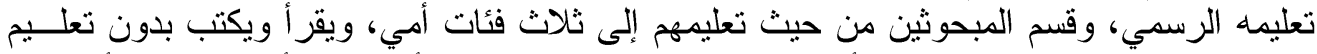

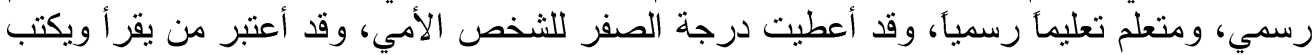

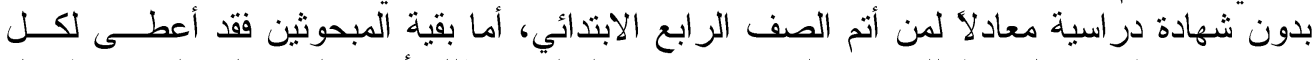

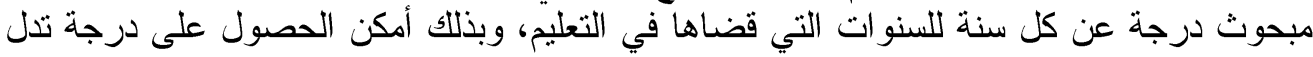

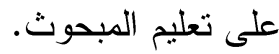

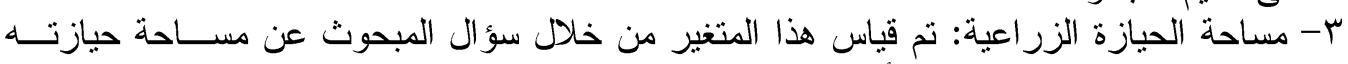

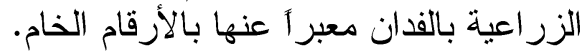

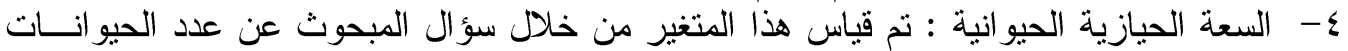
من الإبل و الأغنام، و الماعز ومعبر أ عنه بالأرقام الخام.

Fayoum J. Agric. Res. \& Dev., Vol. 30, No.1, January, 2016 


\section{lor}

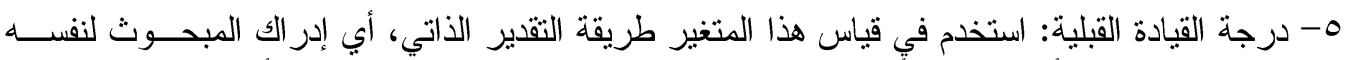

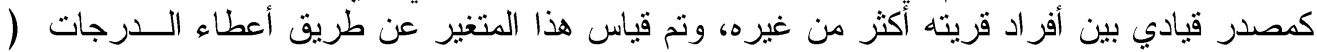

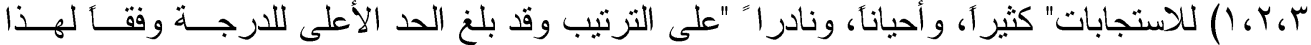

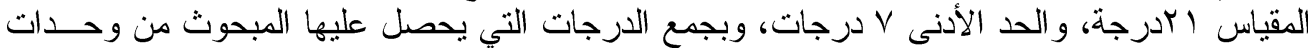

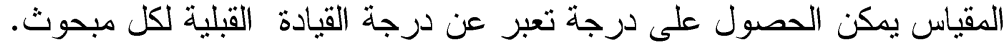

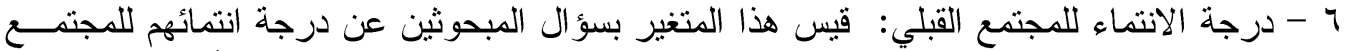

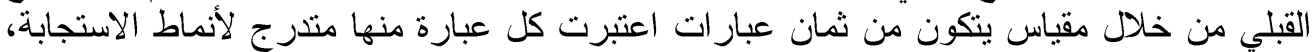

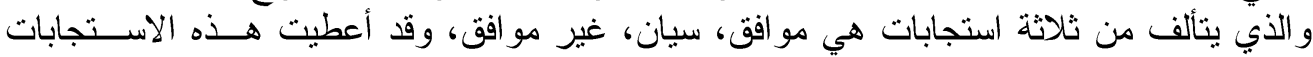

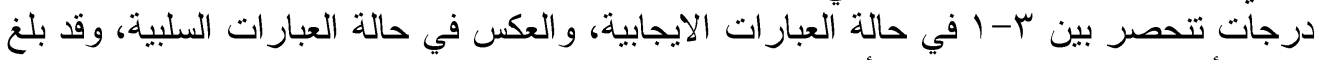

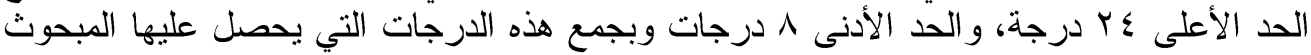
من وحدات المقياس يمكن الحصول على درجة تعبر عن انتماء المبحوث للمجتهع القبلي وبحساب

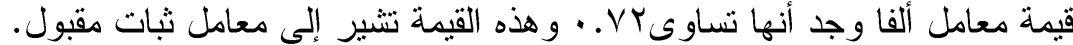

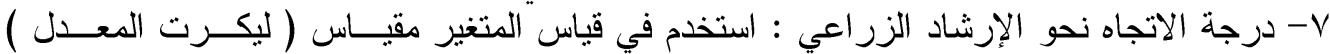

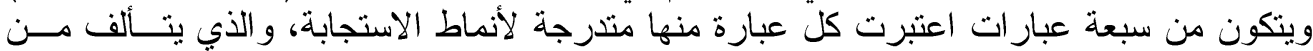

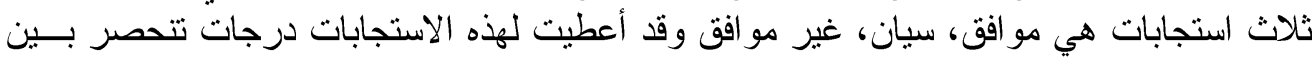

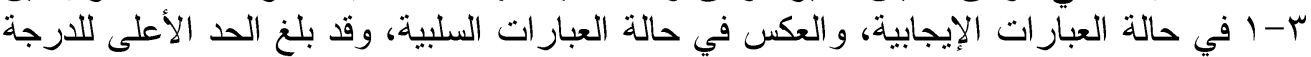

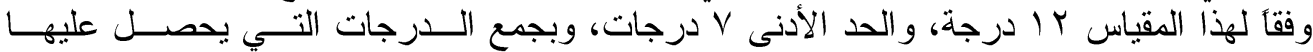

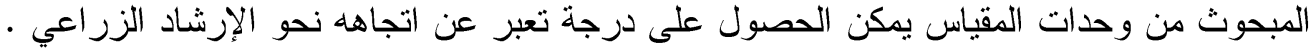

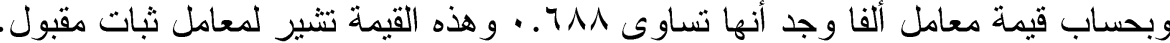

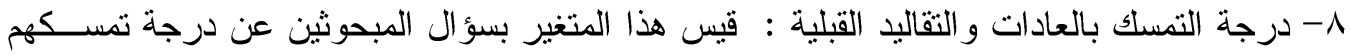

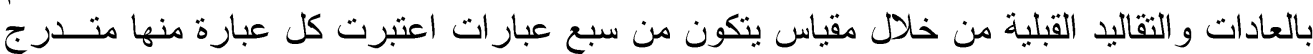

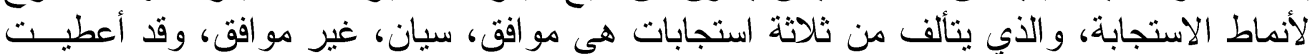

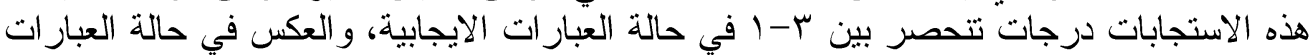

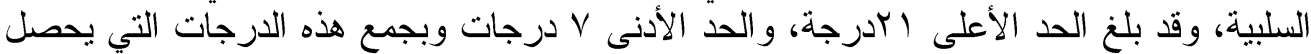

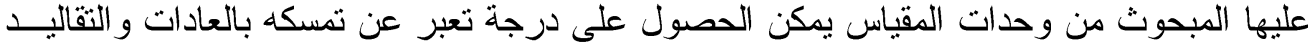

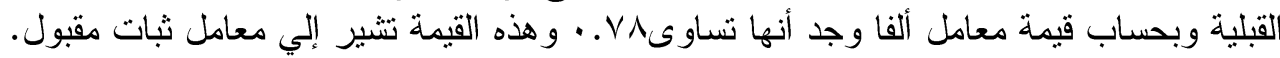

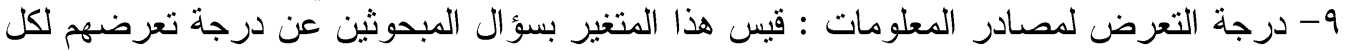

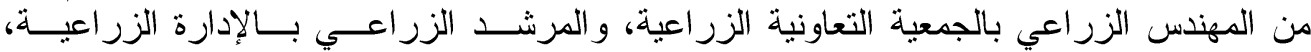

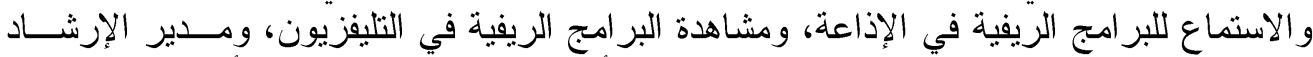

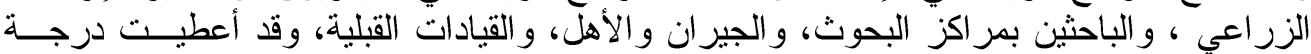

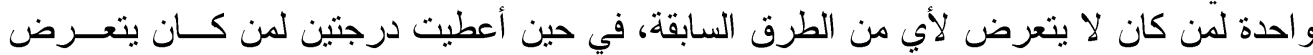

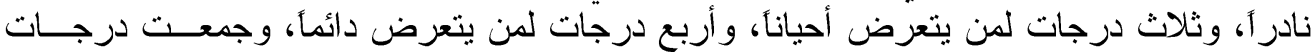

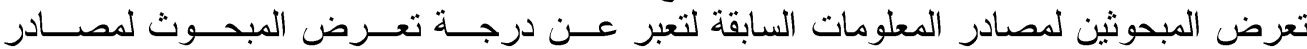

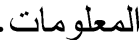
ثانياً : المتغير ماته التابع: أ- قياس درجة أدرالك المبحوثين لمسببات التصحر وهي الدرجة التي يحصل عليها المبحوث نتيجــة

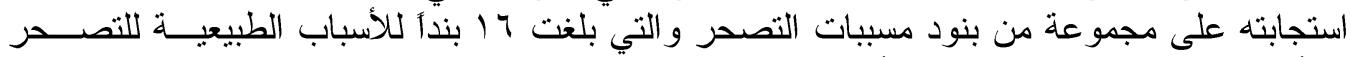

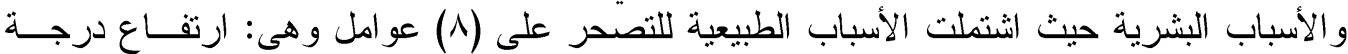

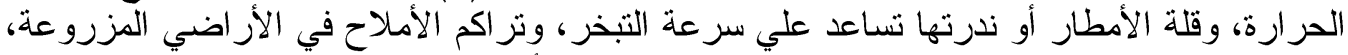

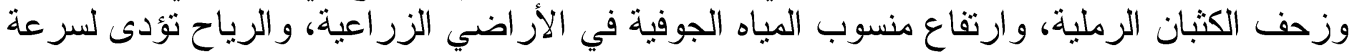

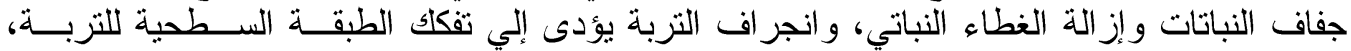

Fayoum J. Agric. Res. \& Dev., Vol. 30, No.1, January, 2016 


\section{$10 \varepsilon$}

و السيول تجرف التربة وتقتلع المحاصيل مما يهدد خصوبة التربة، في حين كانت الأسباب البثـــرية الإنية

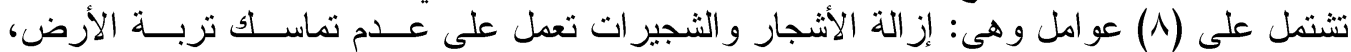
و الرعي الجائر يؤدي إلى إز الذ الغطاء النباتي، الحرث التيل العميق للتربة يؤدى إلي تفكلك الطبقة السطحية

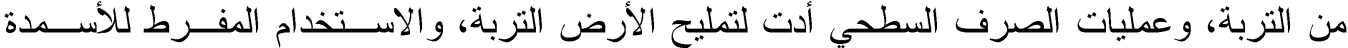

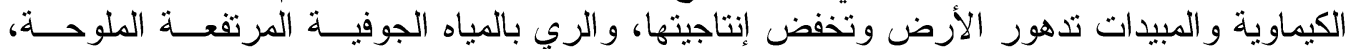

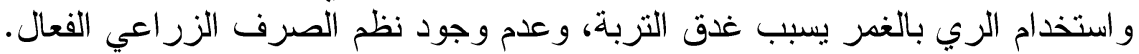

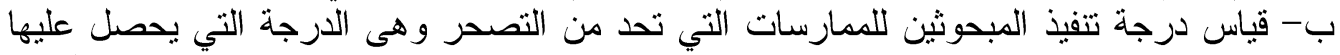

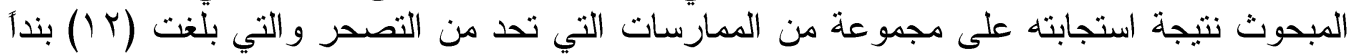

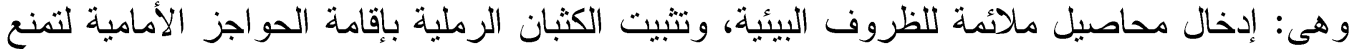

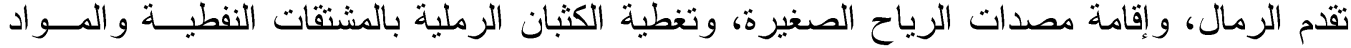

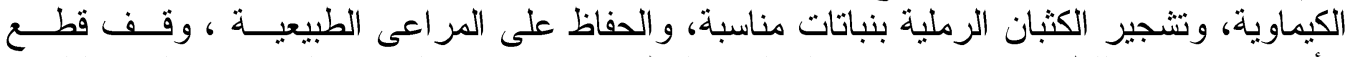

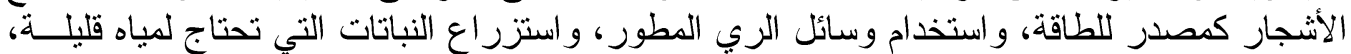

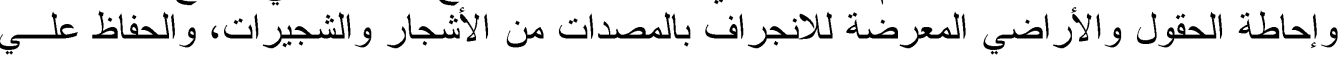

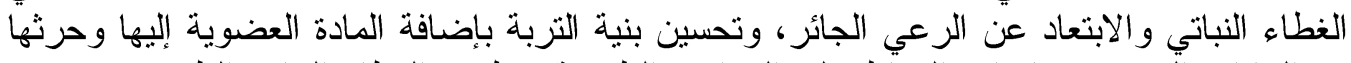

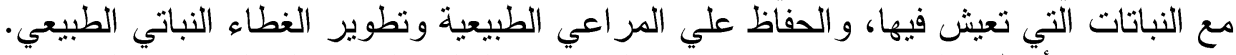

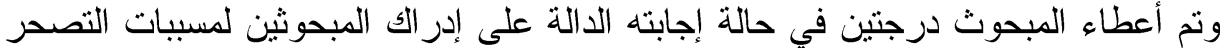

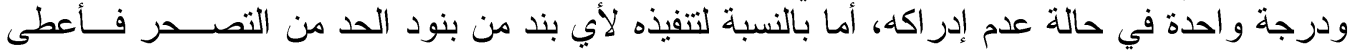

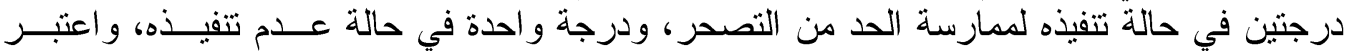

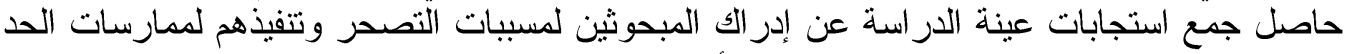

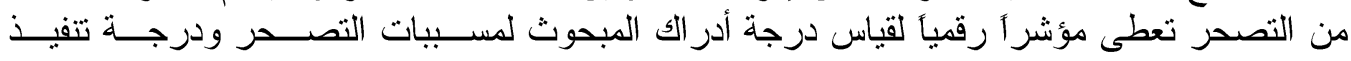

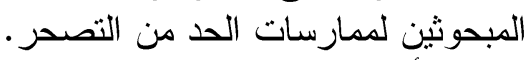

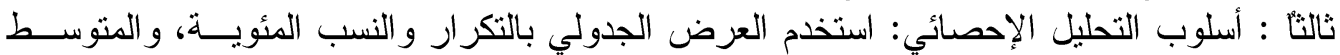

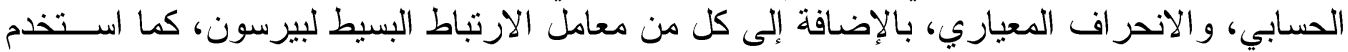

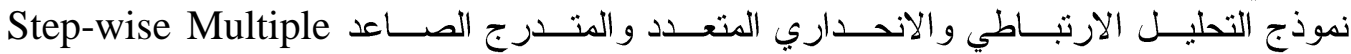
العلافي correlation and regression

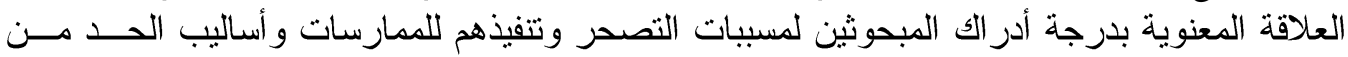

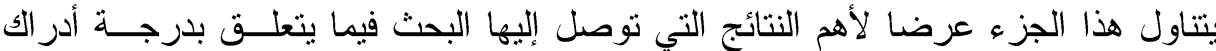

النتائج ومناقشتها

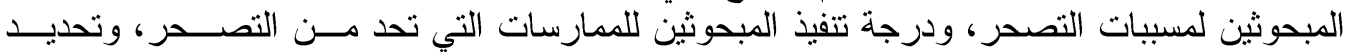

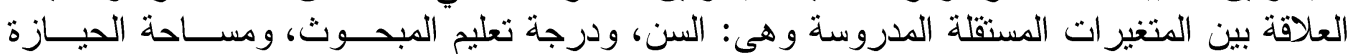

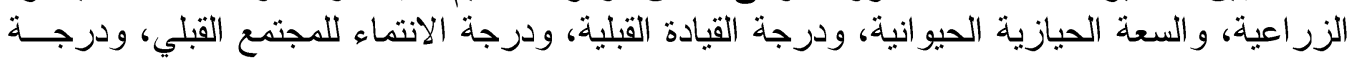

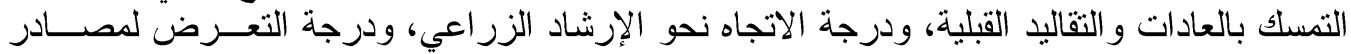

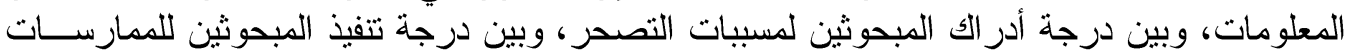

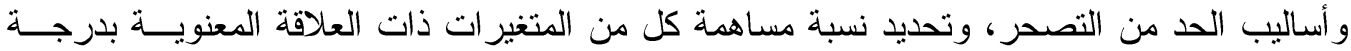

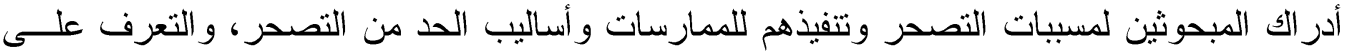

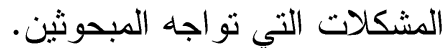

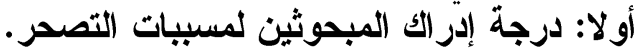

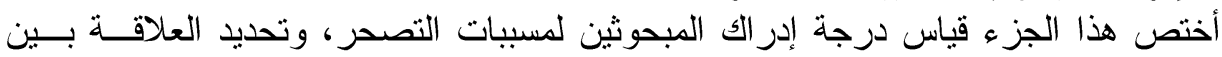

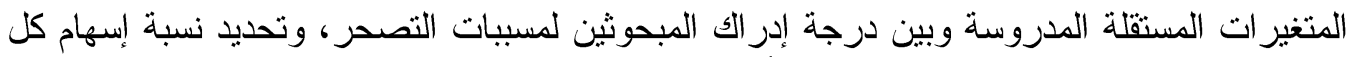

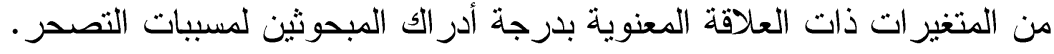

Fayoum J. Agric. Res. \& Dev., Vol. 30, No.1, January, 2016 
درجة إدرالك المبحوثين لمسببات التصحر:

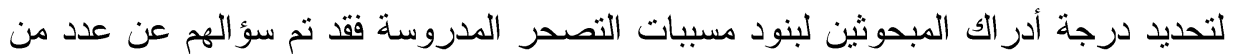

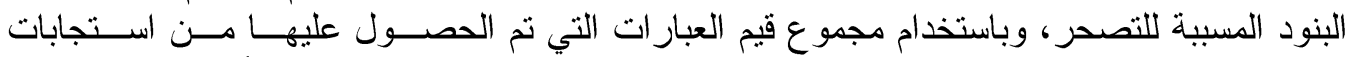

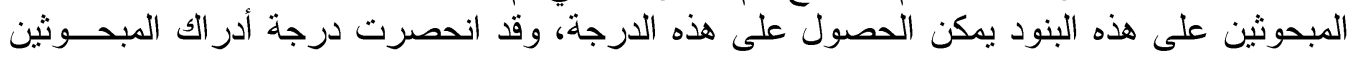

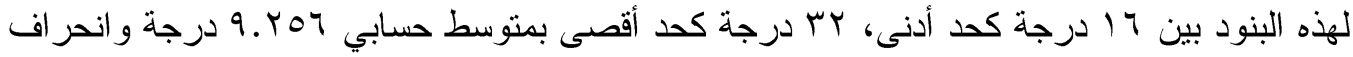

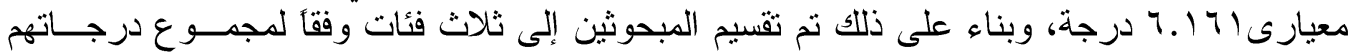

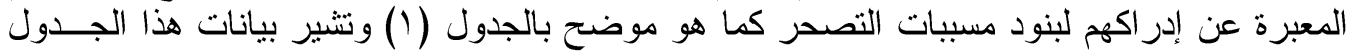

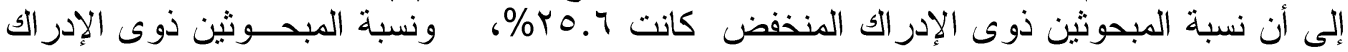

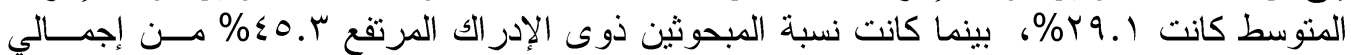

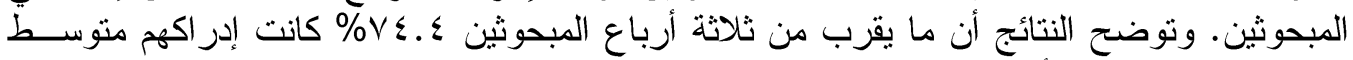

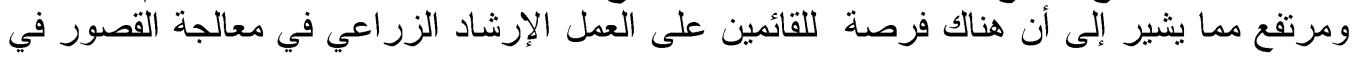

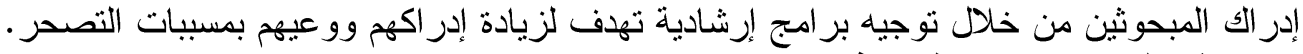

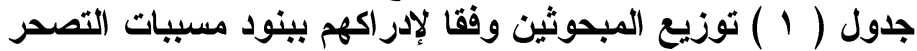

\begin{tabular}{|c|c|c|}
\hline$\%$ & عدد & المبحوثين \\
\hline Y0.7 & $\xi \mu$ & درجة إدر الك منخفضة ( أقل من Y Y درجة ) \\
\hline rq.1 & $\varepsilon 9$ & درجة إدر الك متوسطة ( من Y Y - إلى أقل من YV درجة) \\
\hline$\leqslant 0 . r$ & V7 & درجة إدر الك مرتفعة ( أكثر من V درجة ) \\
\hline $1 \ldots$ & 171 & المجموع \\
\hline
\end{tabular}

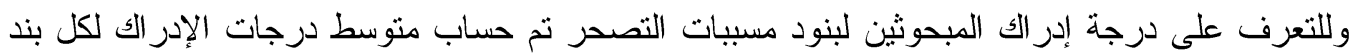

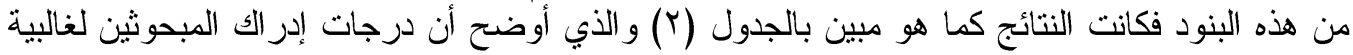

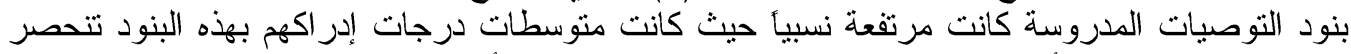

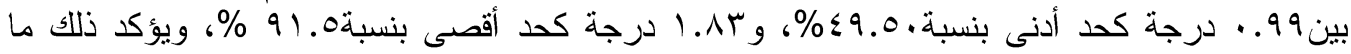

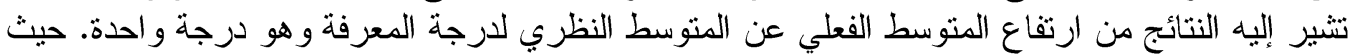

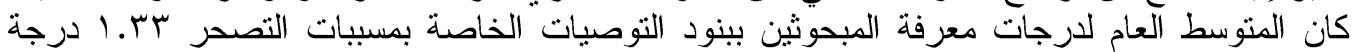

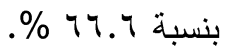

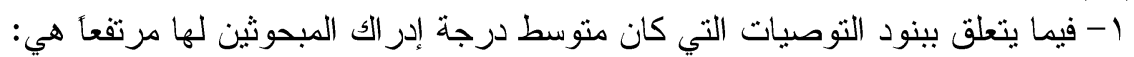

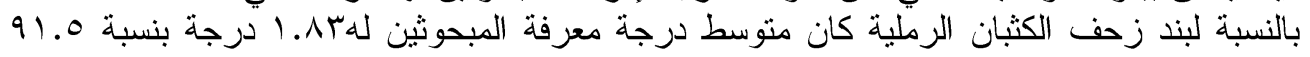

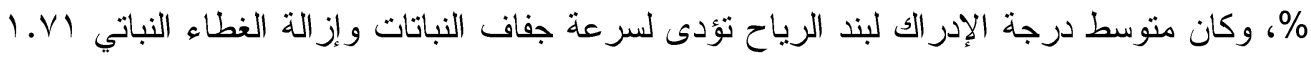

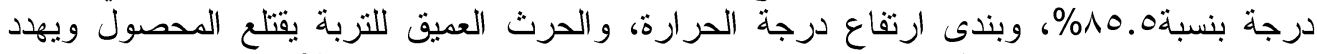
خصوبة النربة كان منوسط درجة إدراكهم لهما

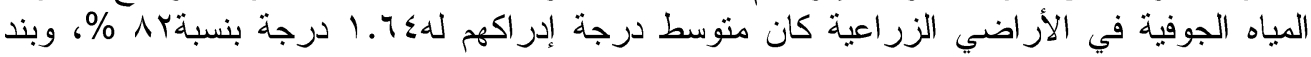

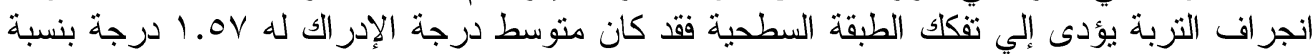

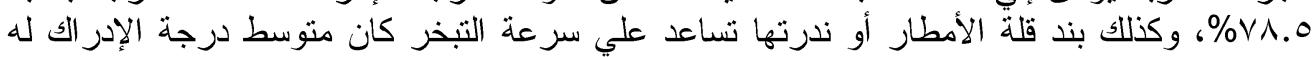

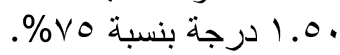

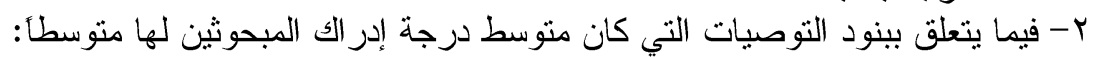

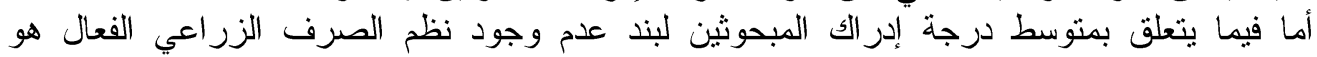

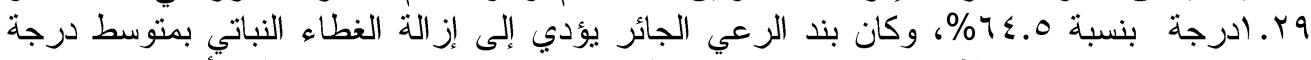

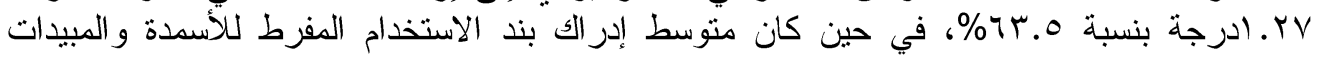

Fayoum J. Agric. Res. \& Dev., Vol. 30, No.1, January, 2016 


\section{7}

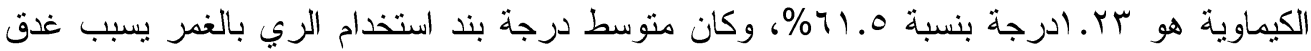

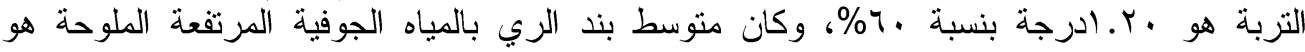

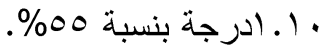

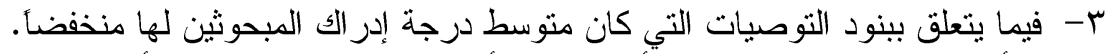

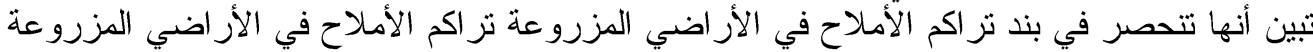

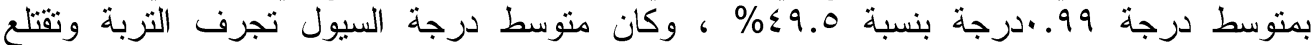

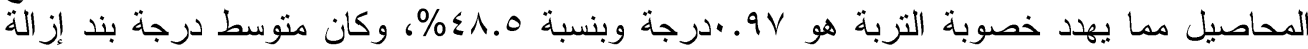

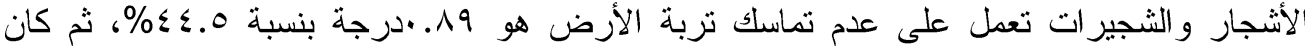

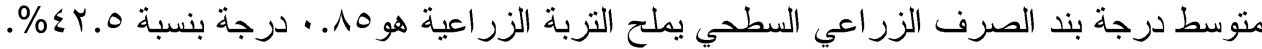

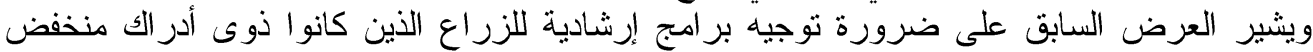

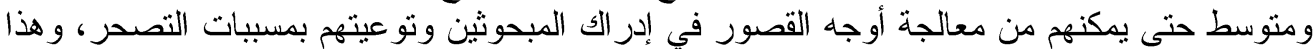

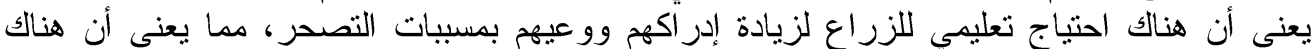

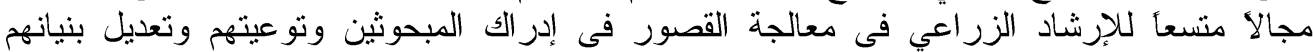

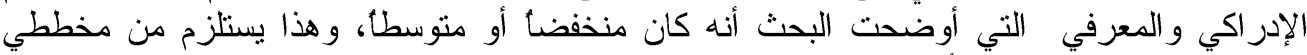

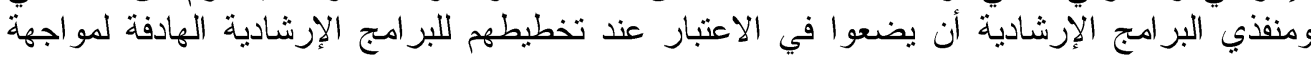

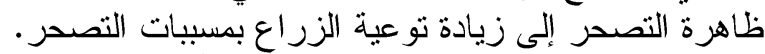
جدول ( r ) المتوسطات والنسب المئوية لادرجات المبحوثين لبنود أدر الك مسببات التصحر

\begin{tabular}{|c|c|c|c|}
\hline$\%$ & متوسط درجات & بنود مسببات التصحر & 3 \\
\hline \multicolumn{4}{|c|}{ إدر الك الأسباب الطبيعية للتصحر } \\
\hline Ar.o & 1.70 & ارتفاع درجة الحرارة & 1 \\
\hline Vo.. & 1.0 & قلة الأمطار أو ندرتها تساعد علي سرعة التبخر & r \\
\hline$\leqslant 9.0$ &. .99 & تز اكم الأملاح في الأر اضي المزروعة & r \\
\hline 91.0 & $1 . \wedge T$ & زحف الكثبان الرملية & $\varepsilon$ \\
\hline$\wedge r_{.} \cdot$ & $1.7 \varepsilon$ & ارتفاع منسوب المياه الجوفية في الأر اضي الزر اعية & 0 \\
\hline 10.0 & 1.11 & الرياح تؤدى لسر عة جفاف النباتات و إز الة الغطاء النباتي & 7 \\
\hline$V \wedge .0$ & $1.0 \mathrm{~V}$ & انجر اف التربة يؤدى إلي تفكك الطبقة السطحية للتربة & $\begin{array}{l} \\
\end{array}$ \\
\hline$\xi \wedge .0$ & $.9 \mathrm{~V}$ & السيول تجرف التربة وتقتلع المحاصبل مما بهدد خصوبة التربة & $\Lambda$ \\
\hline$\Sigma V_{.} \cdot$ & $1 . \varepsilon \wedge$ & المتّوسط الكلى & \\
\hline$\leqslant \varsigma .0$ &. .19 & إز الة الأشجار و الشجير ات تعمل على عدم تماسك تربة الأرض & 9 \\
\hline 74.0 & $1 . Y V$ & الرعي الجائر يؤدي إلى إزالة الغطاء النباتي & 1 . \\
\hline AY.O & 1.70 & الحرث العميق للتربة يؤدى إلى تفكك الطبقة السطحية للتربة & 11 \\
\hline$\sum Y .0$ & $\cdot . \wedge 0$ & عمليات الصرف الزر اعي السطحي أدث لتملح التربة & ir \\
\hline 71.0 & I.r & الاستخدام المفرط للأسمدة و المبيدات الكيماوية تدهور التربة وتخفض & IT \\
\hline $00 .+$ & $1.1 \cdot$ & الري بالمياه الجوفية المرتفعة الملوحة & $1 \leqslant$ \\
\hline $7 \cdot . \cdot$ & $1 . r \cdot$ & استخدام الري بالغمر يسبب غدق التربة & 10 \\
\hline $7 \varepsilon .0$ & 1.19 & عدم وجود نظم الصرف الزر اعي الفعال. & 17 \\
\hline $09 .$. & 1.11 & المتّوسط الكلى & \\
\hline 77.7 & $1 . M$ & المتوسط العام & \\
\hline
\end{tabular}

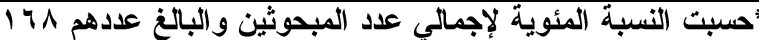

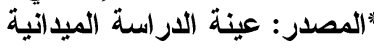

Fayoum J. Agric. Res. \& Dev., Vol. 30, No.1, January, 2016 
ثانياً: العلاقة بين المتغيرات المستقلة المدروسة وبين درجة إدرالك الزراع لمسببات التصحر

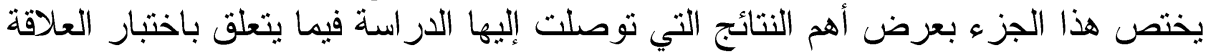

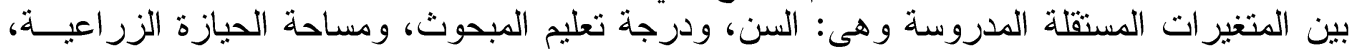

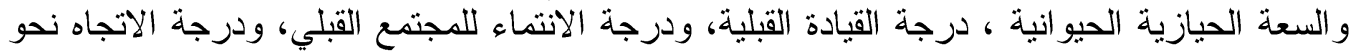

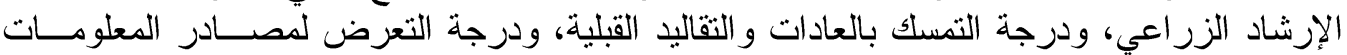

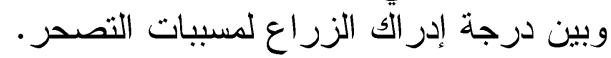

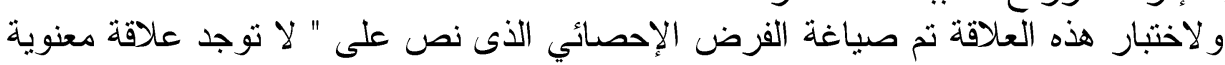

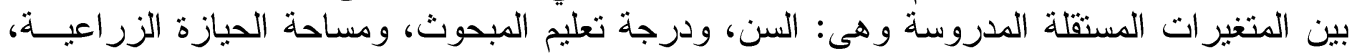

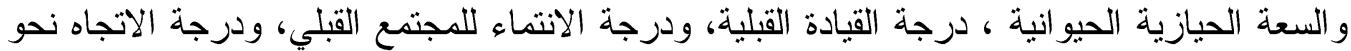

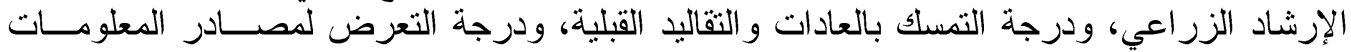

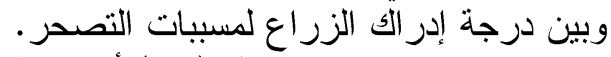

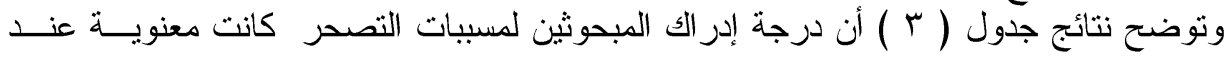

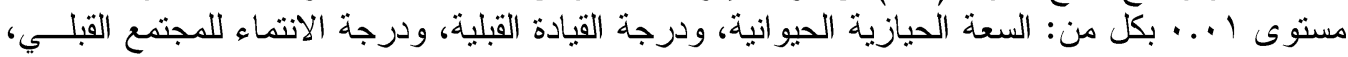

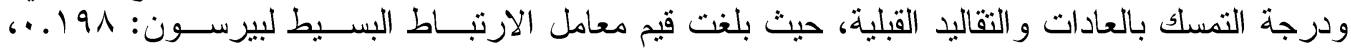

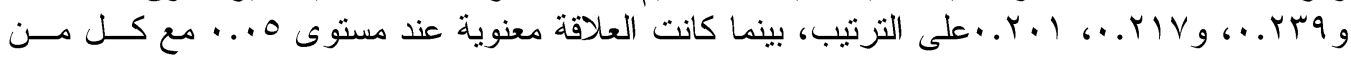

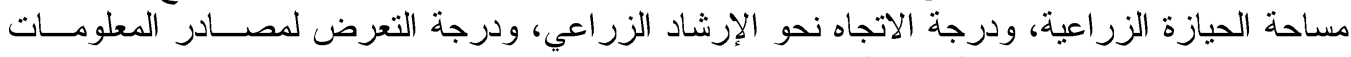

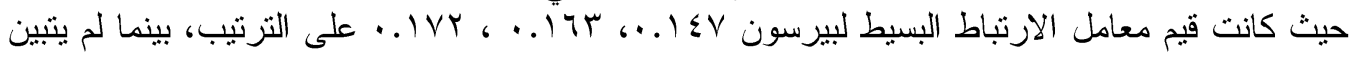

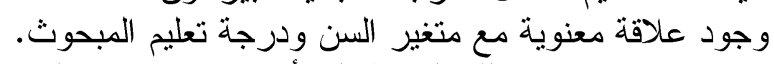

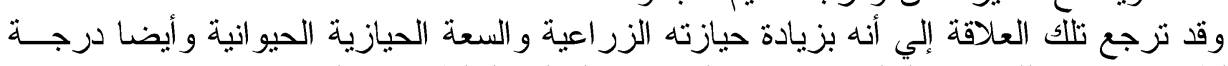

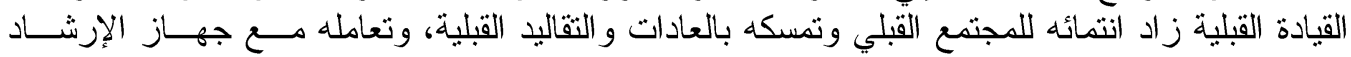

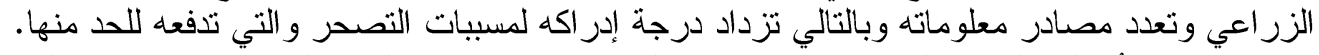

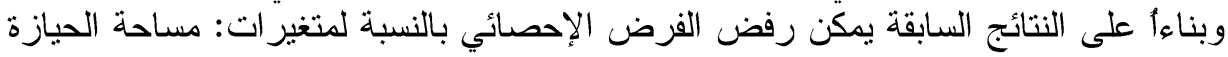

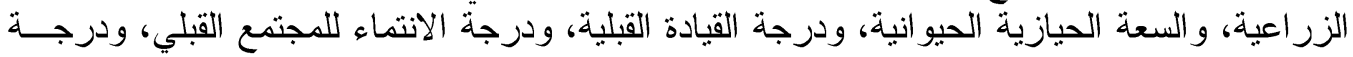

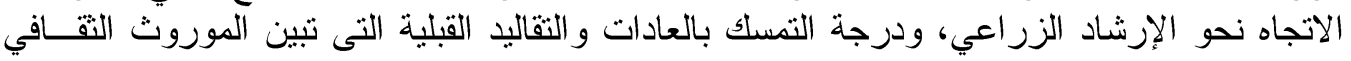

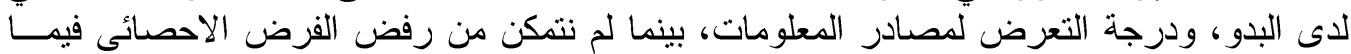

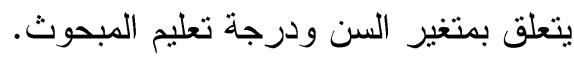

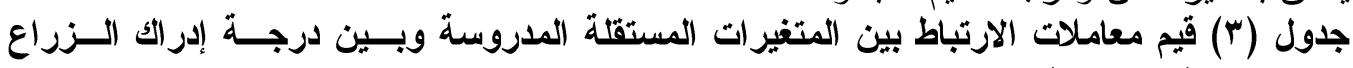

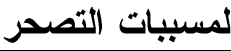

\begin{tabular}{|c|c|c|}
\hline قيم معامل الارتباط & المتغيرات المستقلة المدروسة & ה \\
\hline ת & 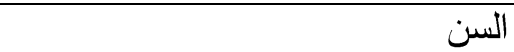 & 1 \\
\hline .110 & درجة تعليم المبحوث & $r$ \\
\hline *.. $\leqslant V$ & مساحة الحيازة الزر اعية & $r$ \\
\hline$* * .191$ & السعة الحيازية الحيو انية & $\varepsilon$ \\
\hline ***rrq & درجة القيادة القبلية & 0 \\
\hline **..YIV & درجة الانتماء للمجتمع القبلي & 7 \\
\hline$\because \cdot .17 \pi$ & درجة الاتجاه نحو الإرشاد الزّراعي & $\mathrm{V}$ \\
\hline$* * . . Y \cdot 1$ & درجة التمسك بالعادات و التقاليد القبلية & $\wedge$ \\
\hline$* . . I V Y$ & درجة التعرض لمصادر المعلومات & 9 \\
\hline
\end{tabular}

Fayoum J. Agric. Res. \& Dev., Vol. 30, No.1, January, 2016 
101

ثالثا: إسهام بعض المتغيرات المستقلة ذات الارتباطات المعنوية بدرجة إدرأك المبحوثين لمسـببات

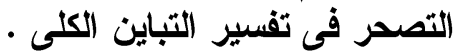

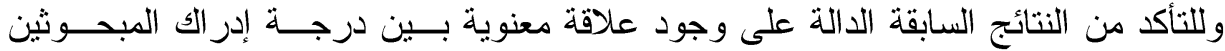

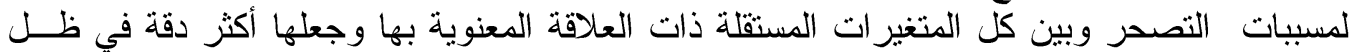
ديناميكية المتغير ات الأخرى، وبأخذ أثز هذه المتغيرات في الاعتبار، فقد تم وضع الفرض الأن الإحصائي

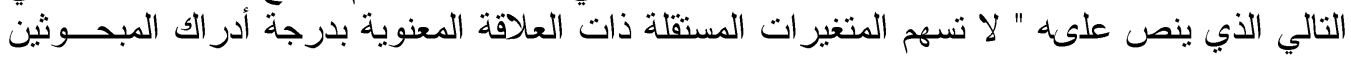

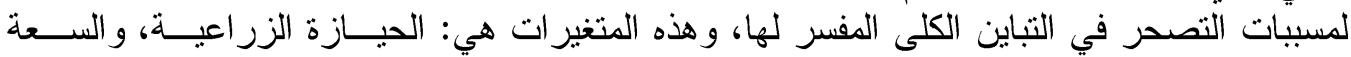

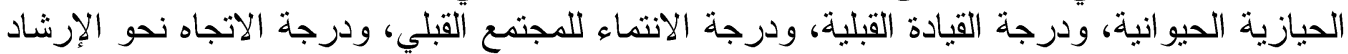

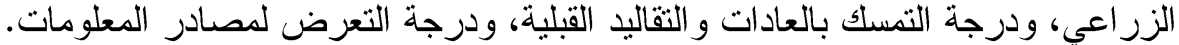

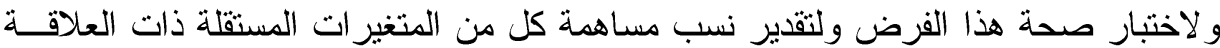

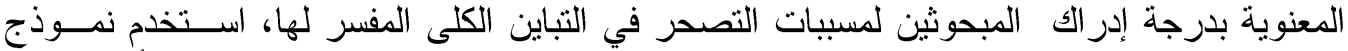

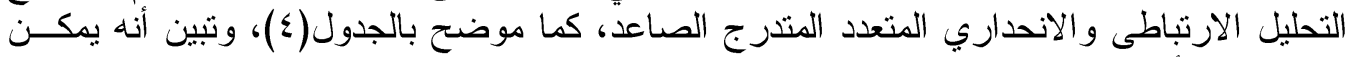

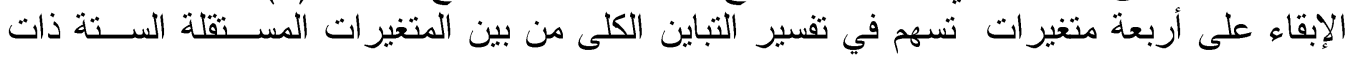

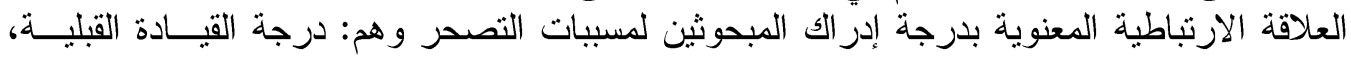
ودرجة الانتماء للمجتمع القبلي، ودرجة التمسك بالعادات والتقاليد القبلية، ودرجة الاتجاه نحونة التحو الإزشاد

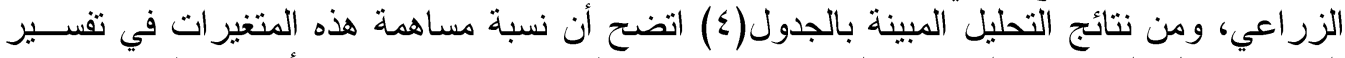

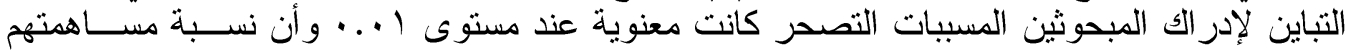

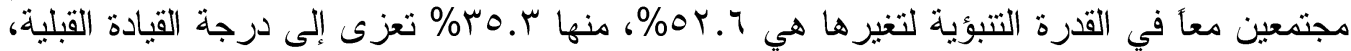

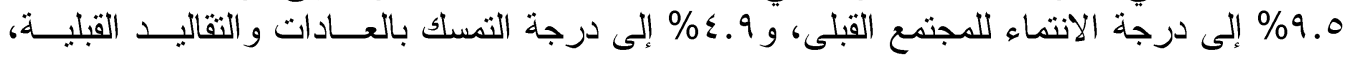

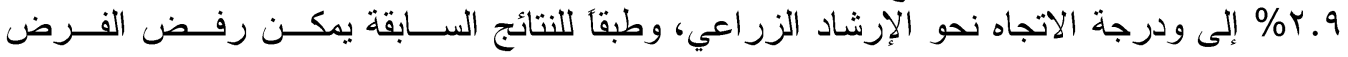
الإحصائي جزئياً وقبول الفرض النظري البديل في هذه الجزئيات فيما يتعلق بكل من المتغيرات الت التالية

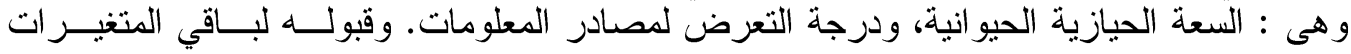
المرتبطة معنوياً وهى: درجة القيادة القبيلة، ودرجة الانتماء للمجتمع القبلي، ودرجة التهـة التمكك بالعادات

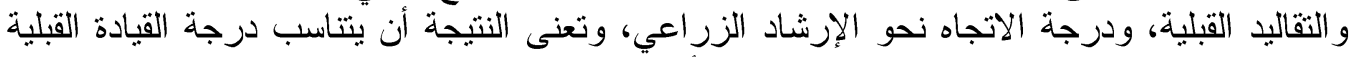

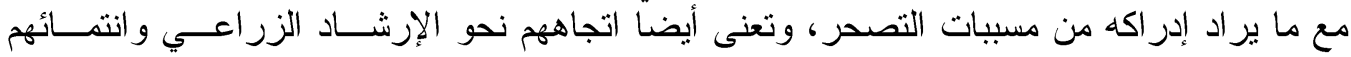

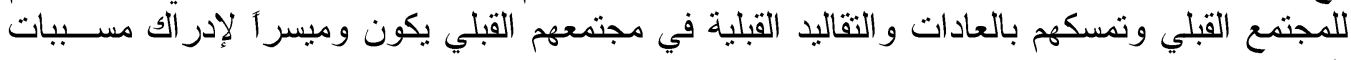

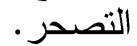

جدول ( ع ) التحليل الارتباطي والاتحداري المتعدد المتدرج الصاعد لعلاقـة المتغيـرات المسـتقلة

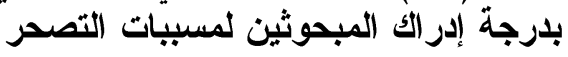

\begin{tabular}{|c|c|c|c|c|c|}
\hline الانحدار & 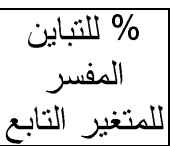 & لللتباين المفسر اكمية & الارتباط المتعدد & المتغير ات الداخلة فى التحليل & خطو ات التحليل \\
\hline$* * \vee \varepsilon . \wedge \cdot Y$ & ro.r & To.r & $.09 \varepsilon$ & درجة القيادة القبلية & الخطوة الأولى \\
\hline$* * 0 \wedge .119$ & 9.0 & $\varepsilon \varepsilon . \wedge$ &. .779 & درجة الانتماء للمجتمع القبلى & الخطوة الثانية \\
\hline **\%.117 & $\varepsilon .9$ & $\leqslant 9 . V$ &.$V \cdot 0$ & درجة التمسك بالعادات و التقالبد البدوية & الخطوة الثالثة \\
\hline **YY.IYA & r.9 & OY.T &.$V Y O$ & درجة الاتجاه نحو الارشاد الزر اعي & الخطوة الر ابعة \\
\hline
\end{tabular}

Fayoum J. Agric. Res. \& Dev., Vol. 30, No.1, January, 2016 
رابعا: درجة تنفيذ المبحوثين لأساليب الحد من التصحر

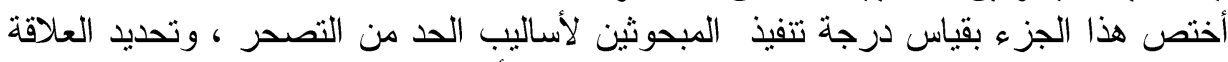

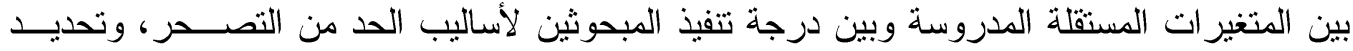

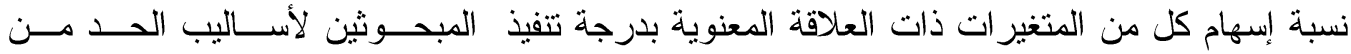

- درجة تنفيذ المبحوثين لأساليب الحد من التصحر

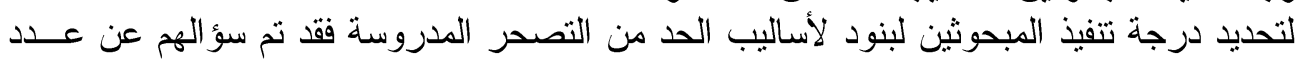

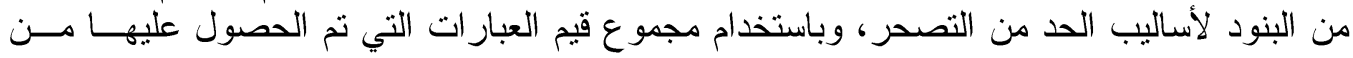

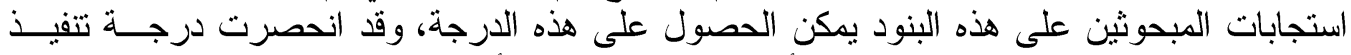

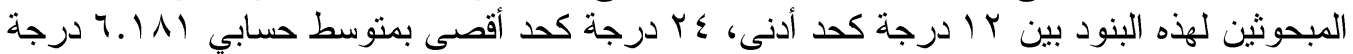

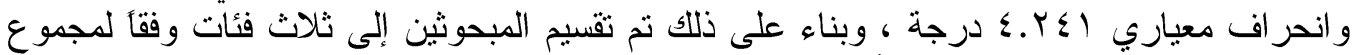

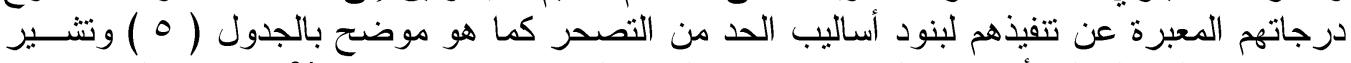

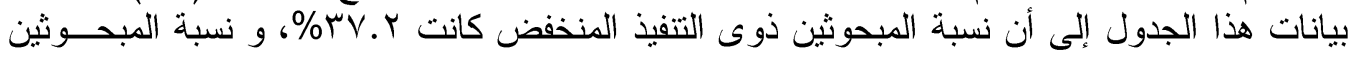

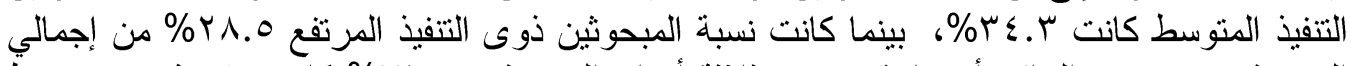

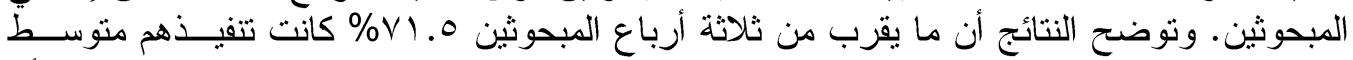

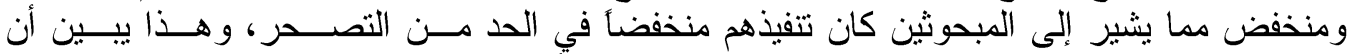

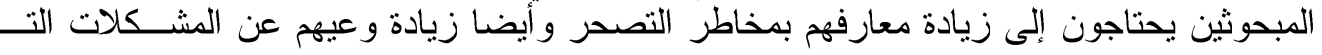

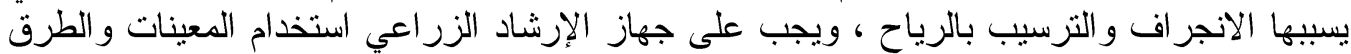

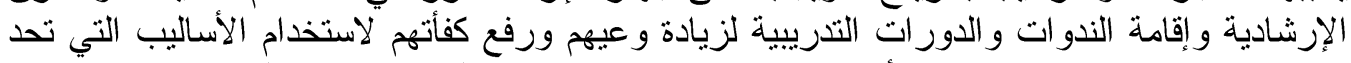

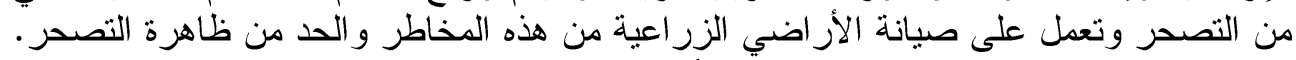

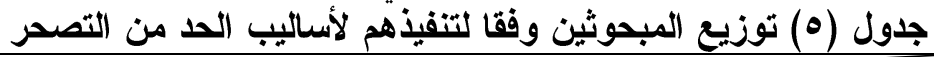

\begin{tabular}{|c|c|c|}
\hline$\%$ & عدد & المبحو ثين \\
\hline TV.r & $7 r$ & درجة تتفيذ منخفضة ( أقل من VI درجة ) \\
\hline$r \varepsilon . r$ & $0 \wedge$ & درجة تتفيذ متوسطة ( من IV - إلى أقل من اY درجة) \\
\hline rA.० & $\sum \Lambda$ & درجة تنفيذ مرتفعة ( أكثر من اب درجة ) \\
\hline $1 \cdots$ & 171 & 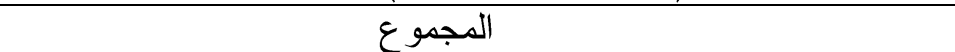 \\
\hline
\end{tabular}

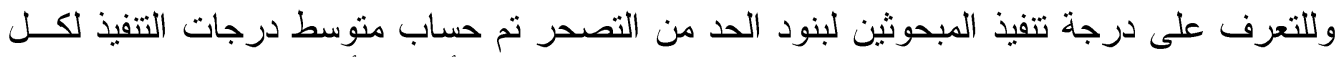

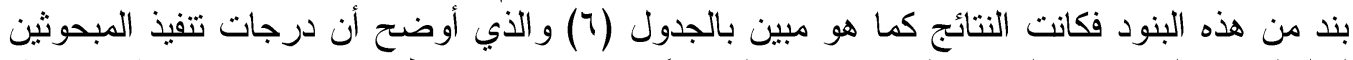

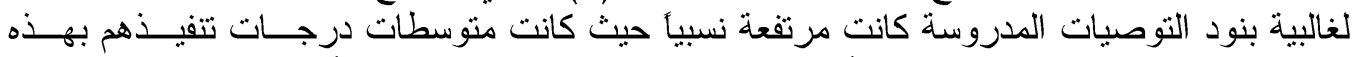

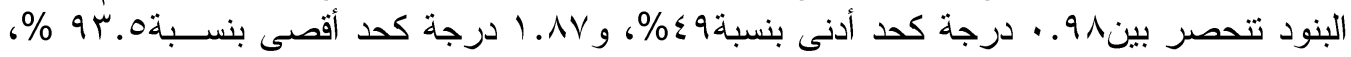

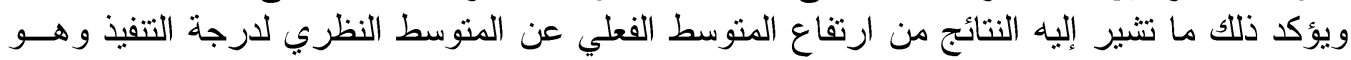

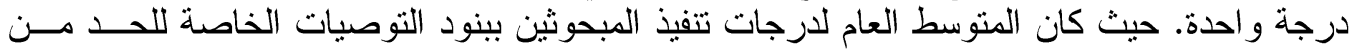

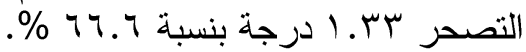

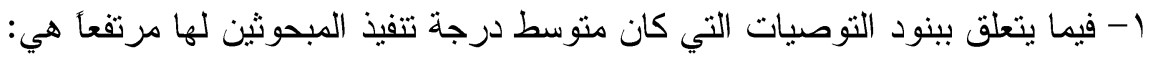

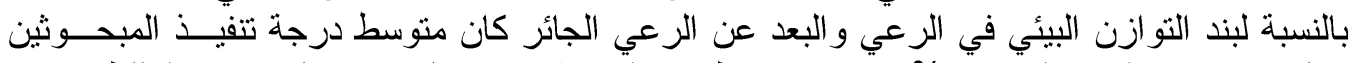

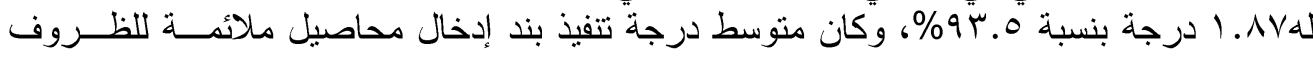

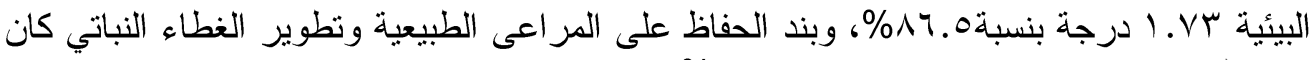

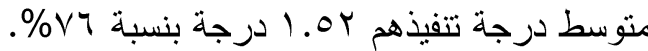
r- فيما يتعلق ببنود التوصيات التي كان متوسط درجة تتفيذ المبحوثين لها متوسطا:

Fayoum J. Agric. Res. \& Dev., Vol. 30, No.1, January, 2016 
17.

أما فيما يتعلق بمتوسط درجة تتفيذ المبحوثين لبند تثبيت الكثبان الرملية بإقامة الحو اجز الأمامية لتمنع التعا

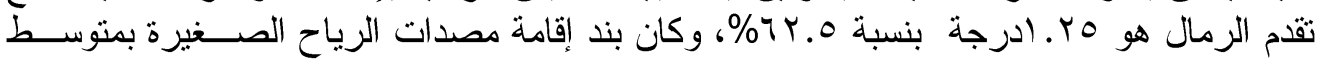

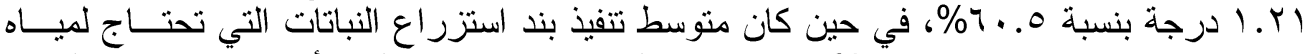

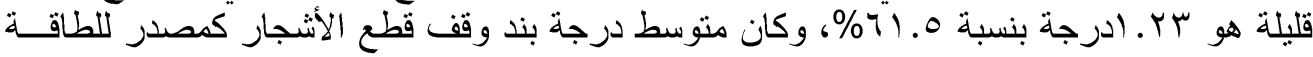

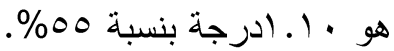

ب- فيما يتعلق ببنود التوصيات التي كان متوسط درجة تتفيذ المبحوثين لها منخفضاً:

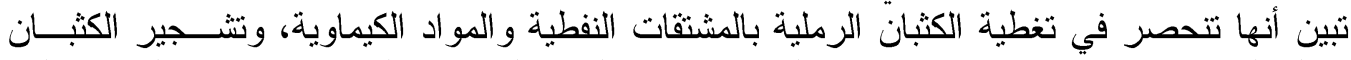

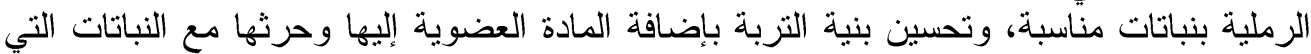

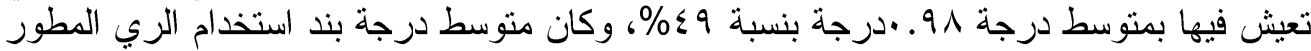

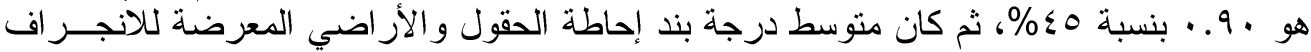

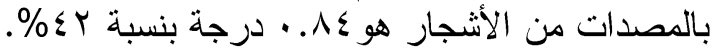

\section{جدول ( 1 ) المتوسطات والنسب المئوية لارجات تنفيذ المبحوثين لبنود الحد من التصحر}

\begin{tabular}{|c|c|c|c|}
\hline$\%$ & درنو التتفيذ & بنود الحد من التصحر & ? \\
\hline A7.0 & I.VT & إدخال محاصيل مالائمة للظروف البيئية & 1 \\
\hline TY.0 & 1.10 & تثبيت الكثبان الرملية بإقامة الحو اجز الأمامية لتمنع تقدم الرمال & r \\
\hline $7 . .0$ & $1 . Y 1$ & إقامة مصدات الرياح الصغيرة & r \\
\hline$\leqslant 9$. &. .91 & تغطية الكثبان الرملية بالمشتقات النفطية و المو اد الكيماوية & $\xi$ \\
\hline$\leqslant 9$. &. .91 & تشجير الكثبان الرملية بنباتات مناسبة & 0 \\
\hline VI.. & $1.0 Y$ & الحفاظ على المر اعى الطبيعية وتطوير الغطاء النباتي & 7 \\
\hline $00 .$. & 1.1. & وقف قطع الأشجار كمصدر للطاقة & $\mathrm{V}$ \\
\hline$\leqslant 0$. & .9 . & استخدام وسائل الري المطور & $\Lambda$ \\
\hline 71.0 & I.YT & استزر اع النباتات التي تحتاج لمياه قليلة & 9 \\
\hline$\sum Y_{.}$ & $\cdot . \wedge \Sigma$ & إحاطة الحقول و الأر اضي المعرضة للانجر اف بالمصدات من الأشجار & 1 . \\
\hline$\leqslant 9$. & $.9 \wedge$ & تعيش فينا بنية التربة بإضافة المادة العضوية إليها وحرثها مع النباتات التي & 11 \\
\hline 94.0 & I.AV & التو ازن البيئي في الرعي و البعد عن الرعي الجائر & IY \\
\hline $91 .$. & I.YY & المتوسط الإم & \\
\hline
\end{tabular}

خامساً: العلاقة بين المتغيرات المستقلة المدروسة وبين درجة تنفيذ المبحوثين لبنود الحد من التصحر

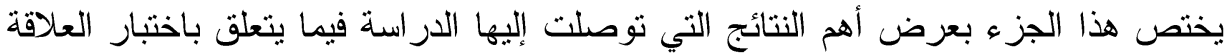

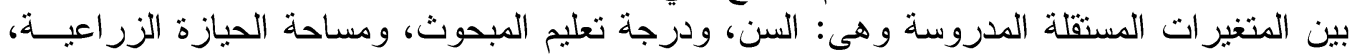

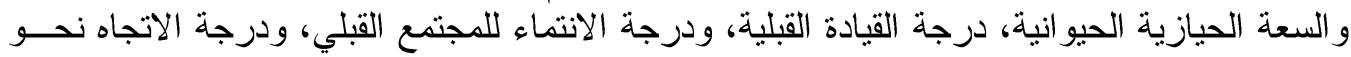

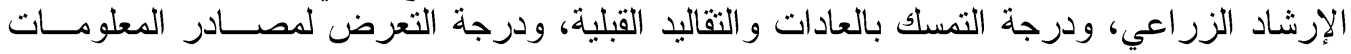

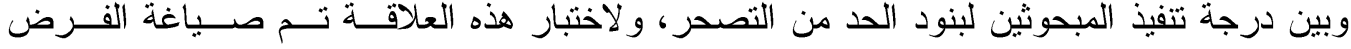

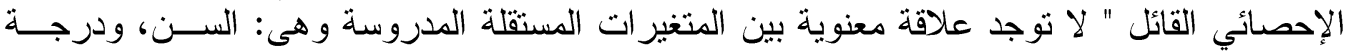

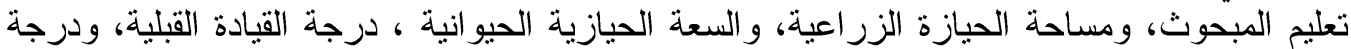

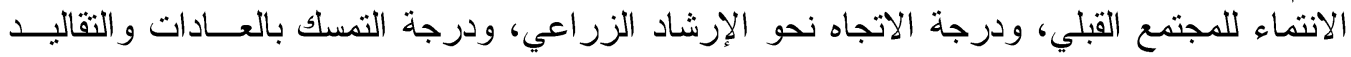

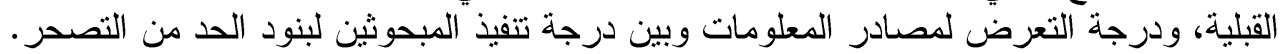

Fayoum J. Agric. Res. \& Dev., Vol. 30, No.1, January, 2016 
171

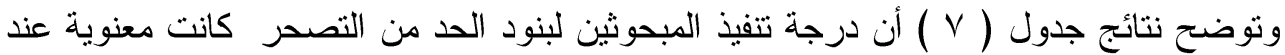

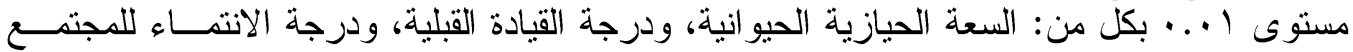

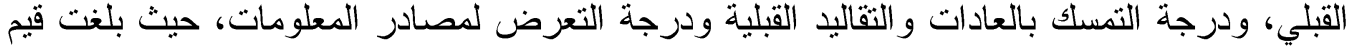

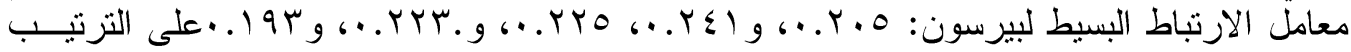

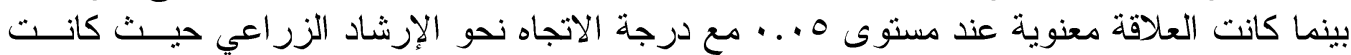

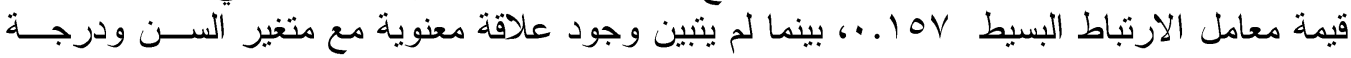

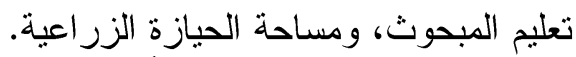

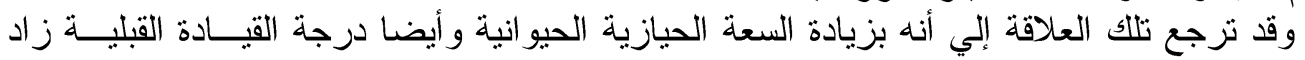

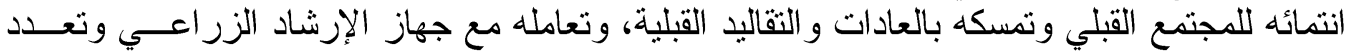

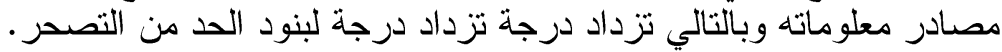

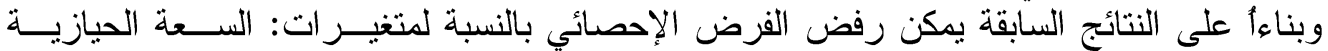

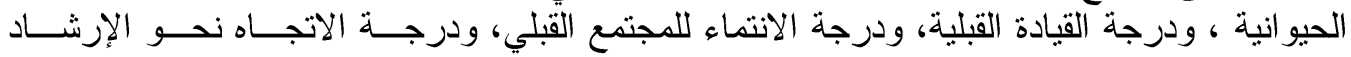

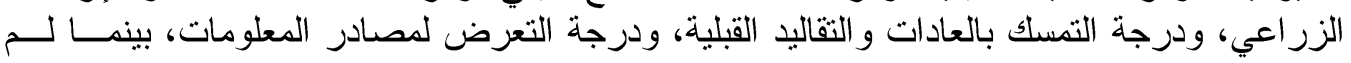
نتمكن من رفض الزرخ الفرض الاحصائى فيما يتعلق بمتغير السن ودرجة تعليم المبحوث، ومساحة الحيازة

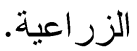

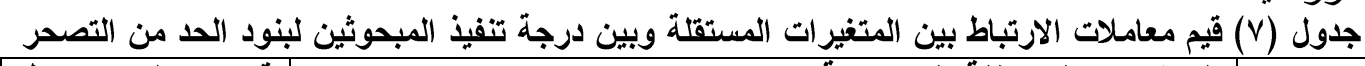

\begin{tabular}{|c|c|c|}
\hline |قيم معامل الارتباط & المتغير ات المستقلة المدروسة & م \\
\hline .14 & السن & 1 \\
\hline .117 & درجة تعليم المبحوث & r \\
\hline $.1 \times 9$ & مساحة الحيازة الزر اعية & $\mu$ \\
\hline$* * . Y .0$ & السعة الحيازية الحيو انية & $\varepsilon$ \\
\hline$* * . Y \leq 1$ & درجة القيادة القبلية & 0 \\
\hline$* *$ * YYO & درجة الانتماء للمجتمع القبلي & 7 \\
\hline$* .10 \mathrm{~V}$ & درجة الاتجاه نحو الإرشاد الزّراعي & $\mathrm{V}$ \\
\hline **. . YYT & درجة التمسك بالعادات و التقاليد القبلية & $\Lambda$ \\
\hline$* * .19 \mu$ & درجة التعرض لمصادر المعلومات & 9 \\
\hline
\end{tabular}

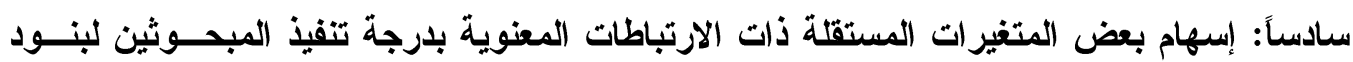

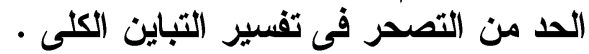

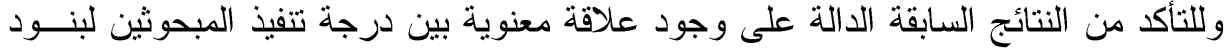

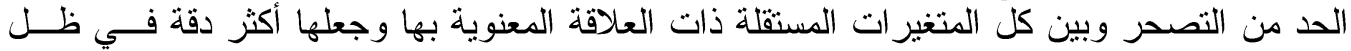

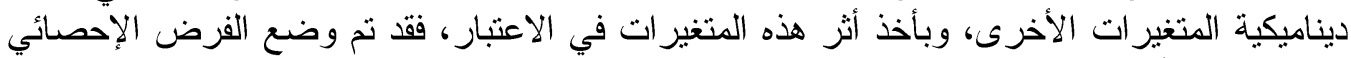

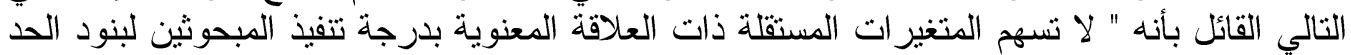

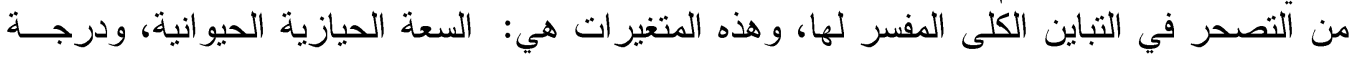

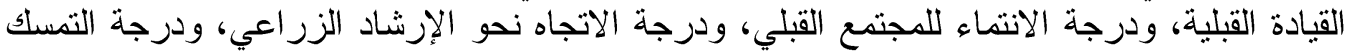

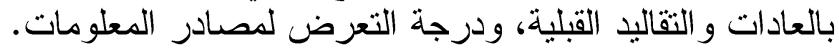

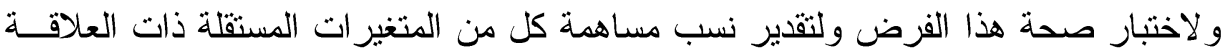

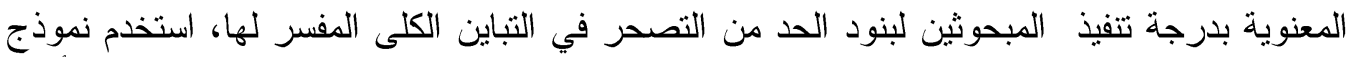

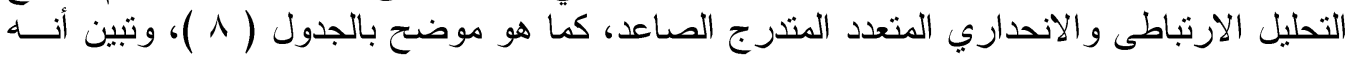

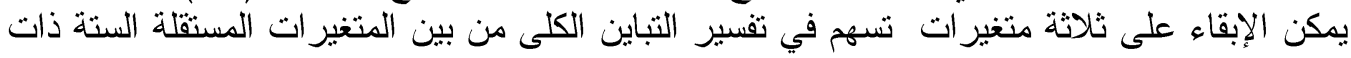

Fayoum J. Agric. Res. \& Dev., Vol. 30, No.1, January, 2016 
$17 r$

العلاقة الارتباطية المعنوية بدرجة تتفيذ المبحوثين لبنود الحد من التصحر وهم: درجة القيادة القبلية،

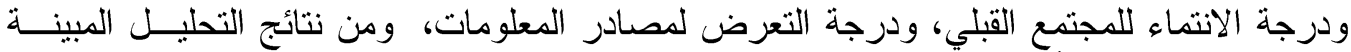

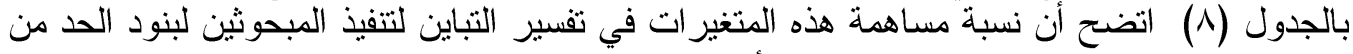

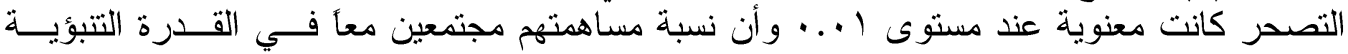

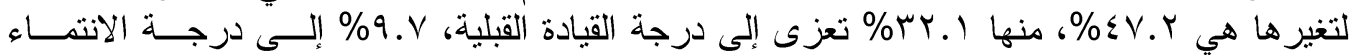

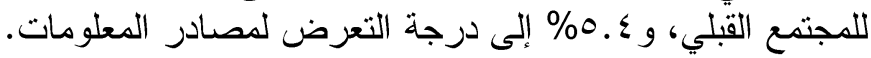

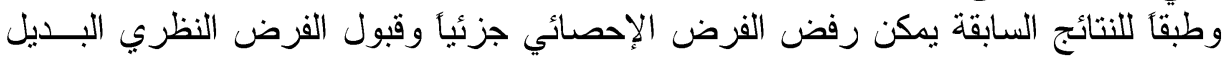

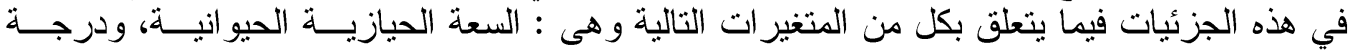

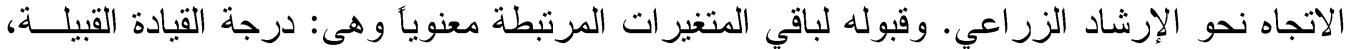

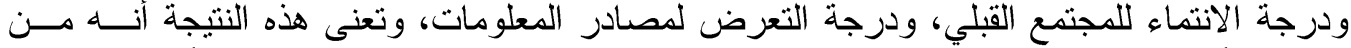

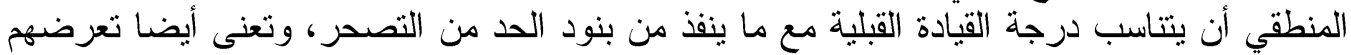

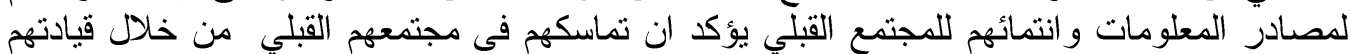

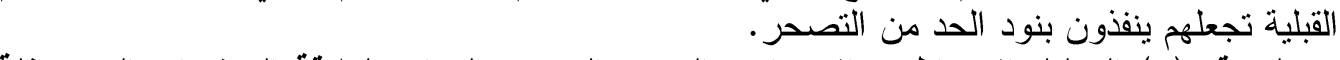
جدول رقم (^) التحليل الارتباطي والانحداري المتعدد المتدرج الصاعد لعلاقة المتغيرات المســتقلة بلرجة تنفيذ المبحوثين لبنود الحد من التصحر التصني

\begin{tabular}{|c|c|c|c|c|c|}
\hline معامل & 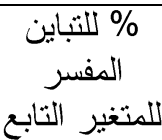 & للتباين التزفسر اكمية & المعتباط & المتغير ات الداخلة فى التحليل & خطو ات التحليل \\
\hline$* * \tau \xi . \Gamma \cdot Y$ & Tr. & TY. & .070 & درجة القيادة القبلية & الخطوة الأولى \\
\hline ***々八.|1. & $9 . \mathrm{V}$ & $\$ 1.1$ & (. & درجة الانتماء للمجتمع القبلى & الخطوة الثانية \\
\hline$* *$ * $9.11 \varepsilon$ & 0.5 & $\sum Y . Y$ &..$T \wedge V$ & درجة التعرض لمصادر المعلومات & الخطوة الثالثة \\
\hline
\end{tabular}

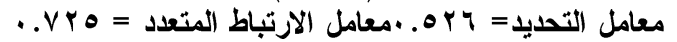

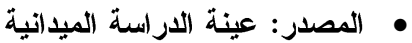

سابعا: المشكلات التى تواجه المبحوثين

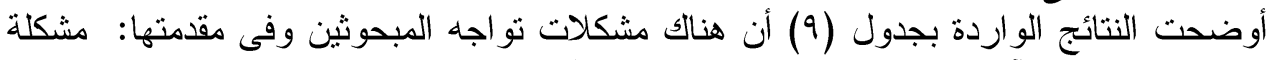

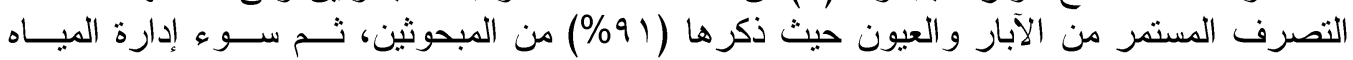

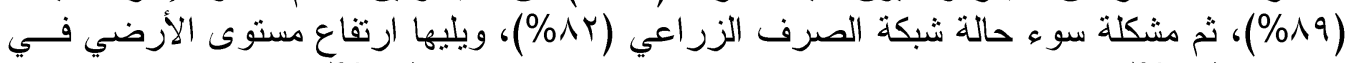

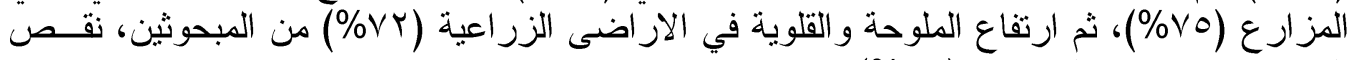

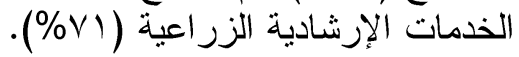
جدول ( 9 ) المشكلات التي تواده الزبة المبحوثين

\begin{tabular}{|c|c|c|}
\hline$\%$ & عدد ع ع & المشكلات \\
\hline 91 & 104 & التصرف المستمر من الآبار و العيون \\
\hline 19 & 10. & سوء إدارة المياه \\
\hline AY & Irᄉ & سوء حالة شبكة الصرف الزر اعي \\
\hline Vo & IYT & ارتفاع مستوى الأرضي في المزارع \\
\hline VY & $\mid Y 1$ & ارتفاع الملوحة و القلوية في الار اضى الزر اعية \\
\hline$\overline{v 1}$ & 119 & نقص الخدمات الإرشادية الزّر اعية \\
\hline
\end{tabular}

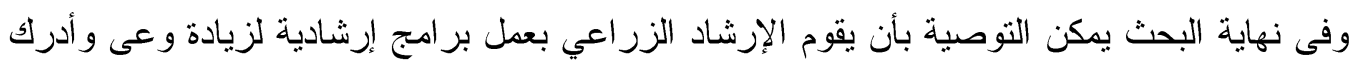

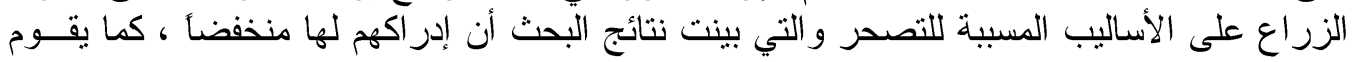

Fayoum J. Agric. Res. \& Dev., Vol. 30, No.1, January, 2016 
$19 r$

القائمين على العمل الزراعي بالتعريف بمخاطر الانجراف بالرياح وذللك باستخدام الوسائل الســمعية و البصرية وتتفيذ دور ات تدريبية لرفع كفاءتهم على استخدام أساليب صياحة الأر اضي للحدي من مخاطر

التصحر

- كما يوصى البحث بإنشاء مصارف مغطاة وتحسين المصارف المفتوحة ، وتطوير النمط الزر اعي المياه

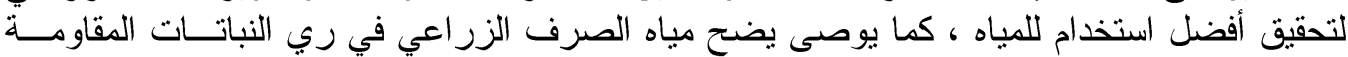

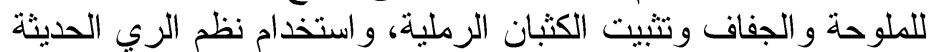

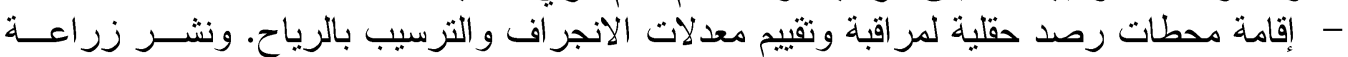

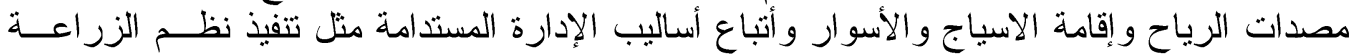

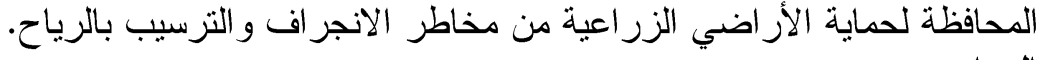

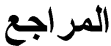

ا- الإدارة العامة للمياه الجوفية بمطروح، بيانات غبر منشورة، مطروح، 10 ــــ.

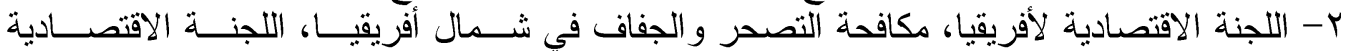

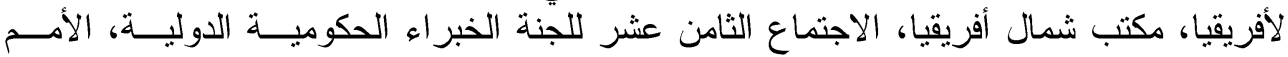

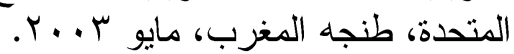

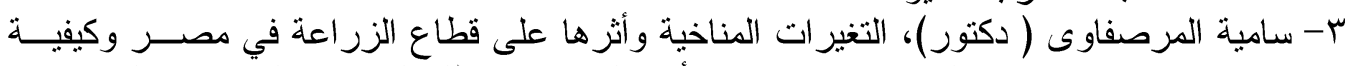

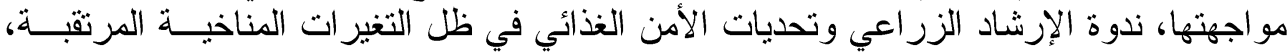

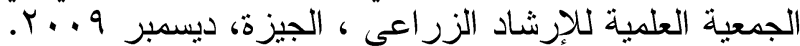

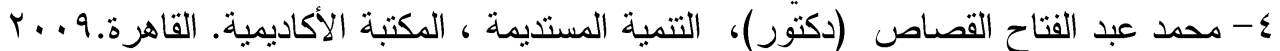

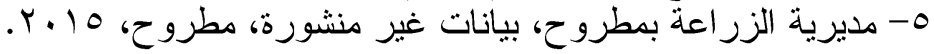

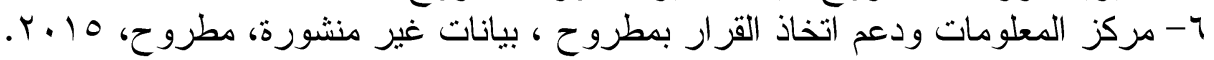

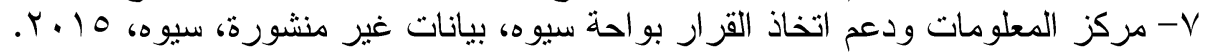

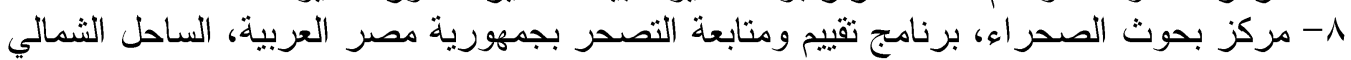

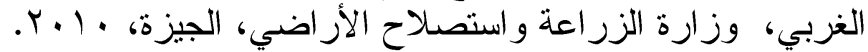

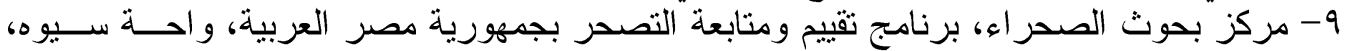

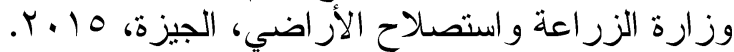
• 1- منظمة الأغذية والزر اعة للأمم المتحدة، تقريز مؤتمر القمة العالمي للأغذية، خمس سنوات بعد

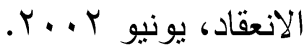

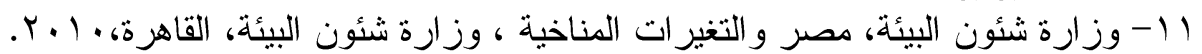

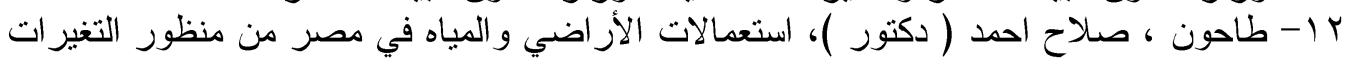

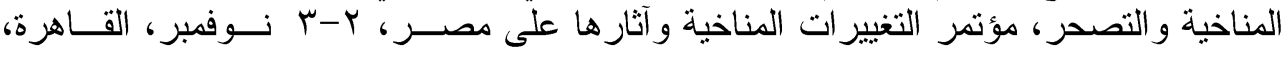

r... 9

13-GDRC The Global Development Research Center, Sustainable Development, definitions. 2008.

14- ( http://www.masr11.com/local2/governorates/item/3803).

Fayoum J. Agric. Res. \& Dev., Vol. 30, No.1, January, 2016 
$17 \varepsilon$

\title{
FARMING METHODS TO CURB DESERTIFICATION AT MATROUH GOVERNORATE
}

\author{
Sayed Abd Elnaby Haikel* Hanan Saad El-Din Hamed* \\ Desert Research Center*
}

\begin{abstract}
The research amid basically at awareness degree of respondents for the reasons leading to desertification, identify implementation degree of reducing desertification methods, identify the most important variables affecting both weariness and implementation degree of reducing desertification methods, to identify the farmers problems faced by the respondents.

Research was conducted Matrouh governorate, a sample of (168) respondents ( $5 \%$ of the population), has been selected. Data were collected by a questionnaire specially prepared to achieve the research objectives, the statistical tools included: percentage and the arithmetic mean, standard deviation, and coefficient of the simple Pearson correlation and multiple regression.
\end{abstract}

\section{The most important findings were:}

- That $25.6 \%$ of respondents with a low degree of understanding of the causes of desertification, and $29.1 \%$ of those with an average degree of perception, and that $45.3 \%$ had high degree of perception.

- Results showed that the awareness degree of respondents to the causes of desertification significant were of correlation at the moral level of 0.01 to each of: Capacity animal possessory, and the degree of tribal leadership, and degree of adherence to custons and tribal traditions, while she it was with a moral relationship at the moral level of 0.05 to size of land holding, attitudes towards agricultural extension, degree of exposure to information sources and there were no significant positive or negative relationship with the rest of the independent variables, namely: age, the degree of the respondent's education.

- It turns out that the percentage contribution of variables in explaining the contrast kidney respondents to the causes of desertification were significant at a level of 0.01 and that the contribution ratio gathered together in the predictive power of change is $52.6 \%$, of which $35.3 \%$ is attributable to the degree of tribal leadership, $9.5 \%$ to the point of belonging to the community of tribal, $40.9 \%$ to the degree of adherence to tribal customs and traditions, to $2.9 \%$ and the degree of the trend toward extension.

- Results showed that $37.2 \%$ of respondents with low implementation of the terms of the reduction of desertification, and $34.3 \%$ of them are middleimplement, and that $28.5 \%$ of them

with high implementation.

Fayoum J. Agric. Res. \& Dev., Vol. 30, No.1, January, 2016 
190

- Results show that the degree of implementation of agriculture to the terms of the reduction of desertification were of a positive correlation at the moral level of 0.01 both: both: Capacity animal possessory, and the degree of leadership tribal, and the degree of belonging to the community tribal, and the degree of adherence to the customs and traditions of the tribal and the degree of exposure to sources of information, while The relationship spirits at a level of 0.05 with a degree trend towards agricultural extension, while it appears that there were significant relationship with the age variable and the degree of education of the respondent, the area of agricultural holdings.

- It turns out that the percentage contribution of these variables in explaining the varition for the implementation of the respondents to the terms of the reduction of desertification were significant at a level of 0.01 and that the contribution ratio gathered together in the predictive power of change is $47.2 \%$, of which $32.1 \%$ is attributable to the degree of tribal leadership, and $9.7 \%$ to a degree belonging to the tribal community, and $5.4 \%$ to the degree of exposure to sources of information.

- results indicated that the most important problems facing respondents are: to act holdover from wells and springs, insufficient of water management, and insufficient of drainage network condition, high level ground on farms, high salinity and alkalinity of soil, lack of agricultural extension services.

Fayoum J. Agric. Res. \& Dev., Vol. 30, No.1, January, 2016 